\title{
Genome-wide identification, organization and phylogenetic analysis of Dicer-like, Argonaute and RNA-dependent RNA Polymerase gene families and their expression analysis during reproductive development and stress in rice
}

\author{
Meenu Kapoor ${ }^{1}$, Rita Arora ${ }^{2}$, Tenisha Lama1 , Aashima Nijhawan², \\ Jitendra P Khurana ${ }^{2}$, Akhilesh K Tyagi ${ }^{2}$ and Sanjay Kapoor*2
}

Address: ${ }^{1}$ University School of Biotechnology, Guru Gobind Singh Indraprastha University, Kashmere Gate, Delhi-110006, India and 2Interdisciplinary Centre for Plant Genomics and Department of Plant Molecular Biology, University of Delhi South Campus, Benito Juarez Road, New Delhi-110021, India

Email: Meenu Kapoor - kapoorsk@genomeindia.org; Rita Arora - rita.arora@south.du.ac.in; Tenisha Lama - kapoors@genomeindia.org; Aashima Nijhawan - aashima_nijhawan@yahoo.com; Jitendra P Khurana - khuranaj@genomeindia.org;

Akhilesh K Tyagi - Akhilesh@genomeindia.org; Sanjay Kapoor* - kapoors@genomeindia.org

* Corresponding author

Published: I October 2008

BMC Genomics 2008, 9:45I doi:10.1186/|47|-2164-9-45।

This article is available from: http://www.biomedcentral.com/l47|-2/64/9/45।

(C) 2008 Kapoor et al; licensee BioMed Central Ltd.

This is an Open Access article distributed under the terms of the Creative Commons Attribution License (http://creativecommons.org/licenses/by/2.0), which permits unrestricted use, distribution, and reproduction in any medium, provided the original work is properly cited.
Received: II March 2008

Accepted: I October 2008

\begin{abstract}
Background: Important developmental processes in both plants and animals are partly regulated by genes whose expression is modulated at the post-transcriptional level by processes such as RNA interference (RNAi). Dicers, Argonautes and RNA-dependent RNA polymerases (RDR) form the core components that facilitate gene silencing and have been implicated in the initiation and maintenance of the trigger RNA molecules, central to process of RNAi. Investigations in eukaryotes have revealed that these proteins are encoded by variable number of genes with plants showing relatively higher number in each gene family. To date, no systematic expression profiling of these genes in any of the organisms has been reported.

Results: In this study, we provide a complete analysis of rice Dicer-like, Argonaute and RDR gene families including gene structure, genomic localization and phylogenetic relatedness among gene family members. We also present microarray-based expression profiling of these genes during 14 stages of reproductive and 5 stages of vegetative development and in response to cold, salt and dehydration stress. We have identified 8 Dicer-like (OsDCLs), 19 Argonaute (OsAGOs) and 5 RNA-dependent RNA polymerase (OsRDRs) genes in rice. Based on phylogeny, each of these genes families have been categorized into four subgroups. Although most of the genes express both in vegetative and reproductive organs, 2 OsDCLs, 14 OsAGOs and 3 OsRDRs were found to express specifically/preferentially during stages of reproductive development. Of these, 2 OsAGOs exhibited preferential up-regulation in seeds. One of the Argonautes (OsAGO2) also showed specific up-regulation in response to cold, salt and dehydration stress.

Conclusion: This investigation has identified 23 rice genes belonging to DCL, Argonaute and RDR gene families that could potentially be involved in reproductive development-specific gene regulatory mechanisms. These data provide an insight into probable domains of activity of these genes and a basis for further, more detailed investigations aimed at understanding the contribution of individual components of RNA silencing machinery during reproductive phase of plant development.
\end{abstract}




\section{Background}

In plants, small RNAs have been widely implicated in varied developmental events and as guide RNAs in many gene silencing pathways [1-6]. These RNAs are usually generated by the activities of Dicers, Argonautes and RNAdependent RNA polymerases (RDRs), which are also sometimes referred to as the core proteins mediating RNA interference. These proteins are involved in the initiation and maintenance of the trigger RNA that is central to this mode of gene regulation. Briefly, initiation of gene silencing involves generation of double stranded RNA (dsRNA) by several mechanisms, for example, bidirectional transcription of DNA, self-complementary RNA foldbacks or RNA-dependent transcription of aberrantly synthesized mRNAs [7]. The complementary dsRNAs are then processed by the RNaseIII-type activities of Dicers into small RNAs, 19-31 nucleotides in length (siRNA or miRNA). Generally, one strand of these RNAs then associates with the silencing effector complexes through the Argonaute proteins. This confers sequence-specific guide functions to these complexes that find target RNAs with sequences complementary to the small RNAs. Silencing/repression of the target genes then occurs by either blocking translation or cleavage of the target mRNA. These small RNAs could also mediate transcriptional gene silencing by recruitment of histone and/or DNA methyltransferases to regulatory sequences of the target genes [8,9].

Dicers and Argonautes are multidomain ribonucleases. Dicers are characterized by the presence of six types of domains, viz., DExD-helicase, helicase-C, Duf283, PAZ, RNaseIII and double stranded RNA-binding (dsRB) domain [10]. All Argonaute proteins share the domain structure that comprises of an N terminal, PAZ, Mid and a C-terminal PIWI domain. The PAZ domain ( 100 a.a) facilitates binding of 3 ' end of siRNA, while, the PIWI domain binds the 5 ' end of siRNA and to the target RNA. This domain has marked similarity with RNaseH family of ribonucleases and it possesses the catalytic amino acid residues required for endonucleolytic cleavage of the target RNA [11]. At least three subfamilies of Argonaute proteins have been identified in eukaryotes [12]. These include the AGO subfamily that is present in plants, animals and yeasts; the Piwi subfamily that has been found only in animals and the worm-specific Argonaute (WAGO) subfamily that are present in C. elegans $[13,14,6]$. Members of both AGO and Piwi subfamilies possess the characteristic DDH metal binding signature residues in their Piwi domains, while most of the WAGO proteins lack them. The Piwi proteins are expressed specifically in the germline cells and are known to interact with a subset of small RNA called Piwi-interacting RNA that are longer (26-31 nt) than siRNA and miRNA (21-24 nt) [13]. This clade of Argonaute proteins have not been identified in any plant species. Recently, however, a novel kind of Argonaute,
OsMEL1 has been described in rice that is involved specifically in male meiosis [15]. RNA-dependent RNA polymerase was first isolated from tomato [16]. These proteins are required for initiation and amplification of silencing signal and they possess a conserved sequence motif that resembles the catalytic $\beta^{\prime}$ subunit of DNAdependent RNA polymerases [17].

Multiple copies of Dicers, Argonautes and RDR genes are known to exist in both plants and animals. With the exception of fission yeast (Schizosaccharomyces pombe) that codes for only one copy each of the Dicer, the Argonaute and the RDR, these proteins are encoded by multigene families in insects, nematodes, mammals and plants [18]. In Arabidopsis, 4 Dicer-like (DCL), 10 Argonautes and 6 RDR genes have been identified. Functions of few of these genes have also been elucidated. Arabidopsis Dicer-like 1 (DCL1), but not DCL2, 3 and 4, has been implicated in biogenesis of miRNA [19]. ARGONAUTE1 (AGO1) regulates floral meristem and organ identity by affecting expression of LEAFY, APETALA1 and AGAMOUS genes. It also affects expression of the polycomb group protein, CURLYLEAF (CLF) that maintains repression of both KNOX and AGAMOUS in vegetative organs [20]. In Drosophila, DICER-1 (Dcr-1) has been found to be essential for miRNA formation and it functions redundantly with Dcr-2 downstream of siRNA production. Dcr-2, on the other hand, has also been implicated in siRNA formation $[21,22]$. In Neurospora crassa, distinct RDR and Argonaute proteins are required for meiotic silencing of unpaired DNA (in nucleus) and RNAi (in cytoplasm; [23]). In Caenorhabditis elegans, the 22 nucleotide endogenous miRNA encoded by lin-4 and let-7 genes are processed by Dcr-1 and these small RNAs regulate lin-14 and lin-41 linked timing of developmental stages in the nematode life cycle [24].

In rice, components of the RNAi machinery are known to be involved in maintenance of undifferentiated cells in shoot apical meristem (SAM), initiation of lateral organ primodia from SAM and floral meristems and formation of male and female germ cells $[15,25,26]$. The present investigation has been carried out with the aim to obtain comprehensive expression overview of all the members of rice Dicer-like, Argonaute and RDR gene families to gain insight into the domains of activity of these genes and to provide a firm foundation for further, more detailed investigations aimed at understanding the contribution of individual components of RNA silencing machinery in regulating gene expression during reproductive development of plants. For this, an in-house generated (previously described; [27]) rice microarray data set comprising of 17 stages of vegetative and reproductive development, along with 5 newly added tissues/developmental stages corresponding to Y-leaf, SAM and three very early stages of 
panicle initiation, was utilized. Where possible, the expression profiles of rice genes have been compared with those in Arabidopsis at similar stages of flower and seed development to identify genes with similar expression profiles in dicots.

\section{Results \\ Identification and structural organization of rice Dicer- like, Argonaute and RDR genes}

Name search using the keywords, Dicer, PAZ, PIWI, Argonaute and RNA-dependent RNA polymerase and HMM analysis resulted in the identification of 8 genes encoding Dicer-like (OsDCL) proteins, 19 for Argonautes (OsAGO) and 5 genes for RDR (OsRDR) in the rice genome (TIGR rice pseudomolecule release 5 ). Besides confirming the previously identified gene members, this exercise revealed two additional OsDCL and one Argonaute encoding loci [10]. The newly identified Dicer-like loci are LOC_Os05g18850 (OsDCL1c) and LOC_Os06g25250 (OsDCL1b) with coding potential of 318 and 300 amino acid polypeptides, respectively (Table 1 ). Protein evidence for only LOC_Os06g25250 was found in the Swiss-Prot/ TrEMBL database (accession number: Q69KJ0). Search for the conserved domains by Simple Modular Architecture Research Tool (SMART) analysis and in NCBI databases revealed the presence of only RNaseIII and dsRB domains in these proteins, while in most other OsDCLs, DExD, Helicase-C, Duf283, PAZ, RNaseIII and dsRB domains, characteristic of plant DCL proteins, were present. OsDCL2b, however, lacked the Duf283 domain and both OsDCL2a and $2 b$ lacked one of the dsRB domains, as reported previously [10]. Maximum number of introns, 26 in number, was found in OsDCL3a that codes for a 1598 amino acid polypeptide.

Of the 19 Argonautes identified in rice in the present study, 17 and 18 genes respectively, were reported recently $[15,28]$. The additional OsAGO (named OsAGO4b) identified in this study, corresponds to the locus LOC_Os04g06770 and is characterized by the presence PAZ and PIWI domains in the putative polypeptide sequence. All OsAGOs code for $\sim 100 \mathrm{kDa}$ basic proteins with pI ranging from 8.07-10. The OsAGOs are characterized by the presence of PAZ domain ( 100 amino acids) towards the amino terminus and PIWI domain ( $\sim 400$ amino acids) at the carboxyl end. As an exception, OsAGO16 was found to code for only the PIWI domain (Table 1). OsAGO15 (LOC_Os01g16850) is characterized by the longest open reading frame of 6711 bp with a coding potential for a 2237 amino acid polypeptide. This protein has been annotated as a retrotransposon protein in TIGR release 5. However, it possesses the Argonaute-specific PAZ and PIWI domains besides the DUF, intergrase core domain (rve) and the reverse transcriptase (RVT_2) domain, characteristic of mobile elements. This gene has also been included as member of the rice Argonaute gene family in previous studies $[15,28]$. Structural studies in other organisms have shown that the PIWI domain of Argonaute proteins folds similar to RNaseH proteins. Consistent with this observation, some Argonaute proteins in both plants and animals are known to cleave the target RNAs that have sequence complementary to the small RNAs $[11,18]$. These catalytic proteins are known to possess three conserved metal chelating residues in the PIWI domain i.e. aspartate, aspartate and histidine (DDH), that function as the catalytic triad. In Arabidopsis AGO1, a conserved histidine at position 798 (H798) was also observed to be critical for the endonuclease activity of AGO1 in vitro [18]. To interrogate which of the OsAGO possessed the conserved catalytic residues and could potentially act as the slicer component of silencing effector complexes, we aligned the PIWI domains of all the OsAGOs using CLUSTALX (Figure 1). Eight proteins, namely OsAGO1a, OsAGO1b, OsAGO10a, OsAGO10b, OsMEL1, OsAGO7, OsPNH1 and OsAGO12, were found to have the conserved DDH/H798 residues. In three OsAGOs, the first aspartate was either missing or was replaced by a glycine or histidine. The other six possessed the conserved DDH triad but the histidine at $798^{\text {th }}$ position in AGO1 was either replaced by serine or a proline (Table 2). At gene structure level, the number of introns in OsAGO varied from 2 in OsAGO2 and SHL4 to 22 in OsAGO1a, OsAGO1b, OsAGO1c and OsAGO1d (Table 1).

All the 5 RDR genes present in the rice genome were found to encode proteins that share a common sequence motif corresponding to the catalytic $\beta^{\prime}$ subunit of DNA-dependent RNA polymerases [17]. The length of the open reading frames of OsRDRs varied from 1311 bp for OsRDR3 to 3657 bp for SHL2, with the coding potential of 437 and 1219 amino acids, respectively. Interestingly, the genomic sequence of SHL2 that encodes the longest open reading frame is interrupted by a single intron, while OsRDR4 that encodes the second longest open reading frame of 3621 bp has 18 intervening sequences as annotated in TIGR (release 5; Table 1).

\section{Phylogeny and chromosomal localization}

To determine evolutionary relatedness of rice Argonautes, RDRs and DCLs with those from mammals, Drosophila, Caenorhabditis elegans, Schizosaccharomyces pombe and Arabidopsis, total protein sequences from these organisms were used to construct an unrooted neighbour-joining phylogenetic tree (Figure 2). Rice and Arabidopsis AGO genes clustered into four subgroups, MEL1, AGO1, AGO4 and ZIPPY (Figure 2A), similar to those described by Nonomura et al. (2007; [15]). In AGO1 subgroup, four rice genes grouped with single Arabidopsis gene AGO1 that is closely related to $A G O 10 / P N H$. These genes have been designated as OsAGO1a, OsAGO1b, OsAGO1c and 
Table I: Structural characteristics of Dicer-like, Argonaute and RNA dependent RNA Polymerase genes identified in rice

\begin{tabular}{|c|c|c|c|c|c|c|c|c|c|}
\hline \multirow[t]{2}{*}{$\begin{array}{l}\text { Serial } \\
\text { No. }\end{array}$} & \multirow[t]{2}{*}{$\begin{array}{l}\text { Gene } \\
\text { Name }\end{array}$} & \multirow{2}{*}{$\begin{array}{c}\begin{array}{c}\text { Accession } \\
\text { Numbers of } \\
\text { Gene Models }\end{array} \\
\begin{array}{c}\text { TIGR } \\
\text { (Release 5) }\end{array}\end{array}$} & \multirow[t]{2}{*}{ TIGR Locus ID } & \multirow[t]{2}{*}{ Coordinates (5'-3') } & \multirow[t]{2}{*}{$\begin{array}{c}\text { ORF } \\
\text { Length (bp) }\end{array}$} & \multicolumn{3}{|c|}{ Protein } & \multirow[t]{2}{*}{$\begin{array}{l}\text { No. of } \\
\text { Introns }\end{array}$} \\
\hline & & & & & & $\begin{array}{l}\text { Lengt } \\
\text { h (a.a.) }\end{array}$ & $\begin{array}{l}\text { Mol. Wt. } \\
\text { (Da) }\end{array}$ & pl & \\
\hline \multicolumn{10}{|c|}{ DICER-like } \\
\hline 1 & OsDCLIa & I2003.m05835 & LOC_Os03g02970 & $1183|84-117435|$ & 5655 & 1884 & 210202.11 & 6.64 & 18 \\
\hline 2 & OsDCL2a & I2003.m08967 & LOC_Os03g38740 & $21469900-21455783$ & 4236 & $|4| 1$ & 158493.38 & 6.86 & 19 \\
\hline 3 & $O s D C L 2 b$ & $\begin{array}{l}\text { |2009.m04723 } \\
\text { |2009.m502|4 } \\
\text { |2009.m502|5 }\end{array}$ & LOC_Os09g14610 & $8649185-8646060$ & 1080 & 359 & 39984.82 & 7.27 & 2 \\
\hline 4 & OsDCL3a & $1200|. m| 2915$ & LOC_Os0lg68120 & $39932566-39922935$ & 4797 & 1598 & 178239.94 & 6.65 & 26 \\
\hline 5 & $O s D C L 3 b$ & $12010 . \mathrm{m} 06268$ & LOC_OsI0g34430 & $18031152-18042777$ & 4719 & 1572 & $|777| 7.08$ & 6.7 & 25 \\
\hline 6 & $\mathrm{SHOI}$ & $\begin{array}{c}\text { |2004.m09269 } \\
\text { |2004.m I0|860 } \\
\text { |2004.m78968 } \\
\text { |2004.m78969 }\end{array}$ & LOC_Os04g43050 & $25262283-25255247$ & 3180 & 1059 & 119863.82 & 7.55 & 25 \\
\hline 7 & OsDCLIc & I2005.m06289 & LOC_Os05g 18850 & $10924931-10927291$ & 957 & 318 & 34954.29 & 8.7 & 2 \\
\hline 8 & OsDCLIb & 12006.m07/73 & LOC_Os06g25250 & $14769389-14772506$ & 903 & 300 & 33335.89 & 5 & 2 \\
\hline \multicolumn{10}{|c|}{ ARGONAUTES } \\
\hline 1 & OsAGOIa & $\begin{array}{l}\text { |2002.m09547 } \\
\text { |2002.m |003।0 }\end{array}$ & LOC_Os02g45070 & $27335674-27324616$ & 3252 & 1083 & | 20463 & 9.43 & 22 \\
\hline 2 & OsAGOIb & $\begin{array}{l}\text { |2004.m09728 } \\
\text { |2004.m |0|624 }\end{array}$ & LOC_Os04g47870 & $28214275-28207729$ & 3309 & 1102 & 121632.35 & 9.86 & 22 \\
\hline 3 & OsAGOIc & |2002.m I0870 & LOC_Os02g58490 & $35762233-35755714$ & 3039 & 1012 & 113158 & 9.53 & 22 \\
\hline 4 & OsAGOId & $\begin{array}{l}\text { |2006.m09|803 } \\
\text { |2006.m09654 }\end{array}$ & LOC_Os06g51310 & $31069900-31076078$ & 3120 & 1039 & 115923.39 & 9.27 & 22 \\
\hline 5 & OsAGO2 & $12004 . \mathrm{m} 10 \mid 47$ & LOC_Os04g52540 & $31020218-31024093$ & 3105 & 1038 & III444.34 & 9.7 & 2 \\
\hline 6 & OsAG03 & |2004.m I0|48 & LOC_Os04g52550 & $31025382-31030370$ & 3333 & 1110 & 122752.46 & 9.45 & 4 \\
\hline 7 & OsAG04a & $\begin{array}{l}|200| . m 08283 \\
|200| . m|504| 5 \\
|200| . m|504| 6 \\
|200| . m|504| 7\end{array}$ & LOC_Os0IgI6870 & $9633946-9628308$ & 2718 & 905 & 100638.84 & 9.32 & 21 \\
\hline 8 & OsAGO4b & $\begin{array}{l}\text { |2004.m0597| } \\
\text { |2004.m35| |3 }\end{array}$ & LOC_Os04g06770 & $3547911-3542867$ & 2739 & 912 & 101739.93 & 9.2 & 21 \\
\hline 9 & OsAGOI 4 & I2007.m05358 & LOC_Os07g09020 & $47|073|-470 \mid 446$ & 3162 & 1053 & 113909.58 & 10 & 21 \\
\hline 10 & OsMELI & I2003.m 0765 & LOC_Os03g58600 & $33319166-33310479$ & 3180 & 1059 & 117034.04 & 9.58 & 21 \\
\hline 11 & OsAGOI3 & |2003.m 0673 & LOC_Os03g57560 & $3275378 I-32760315$ & 3186 & 1061 & $|21023.5|$ & 9.46 & 21 \\
\hline 12 & OsAGOI6 & I2007.m06064 & LOC_Os07gI6224 & $9466401-9459149$ & 1095 & 364 & 40509.71 & 8.07 & 10 \\
\hline 13 & SHL4 & I2003.m08604 & LOC_Os03g33650 & $19198976-19203042$ & 3168 & 1055 & 118110.77 & 9.76 & 2 \\
\hline 14 & OsPNHI & |2006.m0850| & LOC_Os06g39640 & $23539785-23545931$ & 2925 & 974 & 107717.15 & 9.64 & 21 \\
\hline 15 & OsAGOI 7 & I2002.m06078 & LOC_Os02g073IO & $3754861-3748703$ & 2634 & 877 & 98923 & 8.64 & 21 \\
\hline 16 & OsAGOI 2 & I2003.m09795 & LOC_Os03g47820 & $27|1063|-27 \mid 02684$ & 2934 & 977 & 107073.06 & 9.83 & 21 \\
\hline 17 & OsAGOII & I2003.m09796 & LOC_Os03g47830 & $27|27| 03-27|| 4562$ & 2688 & 895 & 99845.06 & 8.94 & 20 \\
\hline 18 & OsAGOI8 & |2007.m07|56 & LOC_Os07g28850 & $16891936-16898240$ & 3270 & 1089 & 118034.34 & 9.57 & 20 \\
\hline 19 & OsAGOI5 & |200|.m0828| & LOC_Os0IgI6850 & $9622035-9610432$ & 6711 & 2237 & 246763.92 & 8.51 & 19 \\
\hline \multicolumn{10}{|c|}{ RNA-DEPENDENT RNA POLYMERASES } \\
\hline I & SHL2 & |200|.m0974| & LOC_Os0Ig34350 & $19272378-19267489$ & 3657 & 1219 & 136533.79 & 7.11 & 1 \\
\hline 2 & OsRDR2 & I2004.m08905 & LOC_Os04g39160 & $23065706-23070916$ & 3411 & 1137 & 126924.77 & 7.56 & 3 \\
\hline 3 & OsRDR4 & $\begin{array}{l}\text { |200|.m07636 } \\
\text { |200|.m97449 } \\
\text { |200|.m97489 }\end{array}$ & LOC_OsOIgI0I40 & $5321158-5304556$ & 3621 & 1207 & 135030.19 & 7.1 & 18 \\
\hline 4 & OsRDRI & |2002.m 0067 & LOC_Os02g50330 & $30727018-30730508$ & 2223 & 741 & 84265 & 6.88 & 2 \\
\hline 5 & OsRDR3 & I200I.m07635 & LOC_OsOIgI0I30 & $5289905-5285242$ & 1311 & 437 & 50679.98 & 6.57 & 6 \\
\hline
\end{tabular}

Values in Bold: Molecular weight and pl calculated by Gene Runner as it was not available in TIGR bp, base pairs; a.a., amino acid; Da, Dalton 
OsAGO1d on the basis of high sequence similarity to AGO1 and similar gene expression profiles to the Arabidopsis gene (described elsewhere). The MEL1 group contains five rice genes including OsMEL1 and the only Arabidopsis gene AGO5. Comparison of full-length OsAGO proteins of this clade revealed that these proteins shared $25-60 \%$ overall identity but their PIWI domains had $75-94 \%$ similar residues. Since only AGO5 and OsMEL1 exhibit similar expression profiles, other genes in this clade have been named OsAGO11-14. In the AGO4 subgroup, two highly similar rice members, LOC_Os04g06770 and LOC_Os01g16870 have been named $\mathrm{OsAGO} 4 a$ and $\mathrm{OsAGO} 4 \mathrm{~b}$ as they share greater similarity with AGO4 (more than $65 \%$ at amino acid level) in comparison to AGO9, AGO8 and AGO6. The animal Argonautes, on the other hand, are grouped into two distinct clades A1 and A2. The phylogenetic relationship of these groups suggests that the plant AGO1 and MEL1 clades had a common lineage with A1, while ZIPPY and AGO4 clades may have diverged from an ancestral lineage that gave rise to A2 clade in animals.

Phylogenetic analysis of rice, Arabidopsis, Zea mays, Populus trichocarpa, C. elegans and Schizosaccharomyces pombe RDR genes revealed that dicot and monocot RDR genes cluster into four clades, I, II, III and IV (Figure 2B). Members in each clade show monophyletic pattern of origin. The rice RDR genes have been named as OsRDR1 to 4 on the basis of sequence similarity with the corresponding proteins in Arabidopsis. LOC_Os01g10130 was named OsRDR3 and LOC_Os01g10140 has been named OsRDR4 on the basis of phylogeny and the results of homology scores of the rice genes with the corresponding Arabidopsis RDR3 and

Table 2: Rice and Arabidopsis Argonaute proteins with missing catalytic residue(s) in PIWI domains

Rice Arabidopsis

S. No.

\begin{tabular}{lllll}
\cline { 2 - 5 } & Argonaute & Motifs* & Argonaute & Motif* \\
\hline 1 & OsAGO2 & DDD/H & AGO2 & DDD/H \\
2 & OsAGO3 & DDD/H & AGO3 & DDD/H \\
3 & OsAGOI3 & -D-/H & AGO4 & DDH/S \\
4 & OsAGOII & GDH/H & AGO9 & DDH/R \\
5 & OsAGOI7 & HDR/C & AGO6 & DDH/P \\
6 & OsAGOI4 & DDH/P & & \\
7 & OsAGOI8 & DDH/S & & \\
8 & OsAGO4a & DDH/P & & \\
9 & OsAGO4b & DDH/P & & \\
10 & OsAGOI5 & DDH/P & & \\
11 & OsAGOI6 & DDH/P & &
\end{tabular}

*Motifs correspond to conserved D760, D845, H986/H798 of Arabidopsis AGOI
RDR4 genes in BLAST searches (data not shown). The RDR genes of C. elegans also originated from a common ancestral gene that diverged from the clades that gave rise to plant and the single yeast gene.

Plant DCL genes form a monophyletic group with OsDCL genes showing high sequence conservation with their counterparts in Arabidopsis (Figure 2C). Dicers from Drosophila (Dcr-1), nematode and humans form one group that is distinct from Drosophila Dicer2 and the only Dicer from $S$. pombe due to absence of the conserved PAZ domain in these proteins (Figure 2C). The newly identified $O s D C L$ loci closely grouped with the highly similar AtDCL1 and OsDCL1. Similar associations were observed when only dsRBa domains of rice and Arabidopsis proteins were used to construct a phylogenetic tree (data not shown). Therefore, we have renamed OsDCL1 as OsDCL1 $a$, and named the two new loci as OsDCL1b and OsDCL1c (Table 1, Figure 2C).

To gain insight into the evolution of multiple AGOs, RDRs and DCLs in rice, we analyzed their genomic distribution by localizing the genes on rice chromosomes (Figure 3; Table 1). Two pairs of rice Argonautes, OsAGO14OsMEL1 and OsAGO1a-OsAGO1b, appear to have originated due to segmental duplications in chromosomes 3 and 7 and chromosomes 2 and 4, respectively. OsAGO13 was located close to OsMEL1 on chromosome 3, which has the maximum number of 5 genes, while the rest of the OsAGO were distributed on chromosomes 1, 2, 4, 5, 6 and 7 (Figure 3). Localization of OsRDR on rice chromosomes showed 3 genes, OsRDR3, OsRDR4 and SHL2 on chromosome 1 while chromosomes 2 and 4 had OsRDR1 and OsRDR2, respectively (Figure 3). None of these genes were found to be located in duplicated segments of the genome.

The OsDCL genes were distributed on 7 chromosomes (Figure 3). Except chromosome 3 that contains OsDCL1 and OsDCL2a, all the other chromosomes $(1,5,6,4,9$ and 10) have single representative of OsDCL. When these data were superimposed with those for segmental duplications (TIGR), OsDCL2a and OsDCL2b were found to lie in duplicated regions of chromosomes 3 and 9. It has been previously shown that at amino acid levels too, these two paralogs share $99 \%$ similarity while at the genomic level these genes differ by a 200 bp deletion within an intron and deletion of a part of Duf domain in OsDCL2b [10]. OsDCL1a, OsDCL1b and OsDCL1c that share significant homology were localized on regions of chromosomes 3, 5 and 6, which are not included in segmental duplication database, suggesting that events other than large segmental duplications might be responsible for their evolution. The expressed sequence tags (EST) showing similarity to these rice Dicer-like genes are present in 


\begin{tabular}{|c|c|c|c|c|c|c|c|c|c|c|c|c|c|c|}
\hline & 15 & & & & & & & & $1 \times$ & & & & & LVK \\
\hline $\mathrm{AGO} 3$ & 893 & KINAKVGGTN & VELVDNIFSF & FK----KEDK & VMF IGADVNH & PAAHDNMS-- & PSIVAVVGTL & NWPEANRYAA & RVKAQS & $\mathrm{KE}$ & EIQGFGETCW & & & -ELIE \\
\hline $\mathrm{AGO} 2$ & 749 & KINGKIGGSN & IQLFGESLPR & IS---GAP- & YMF IGADVNH & PSPGNVES-- & PSIAAVVASV & DQ-GASKYVP & RIRAQ & & VIQHLGDMCK & & & \\
\hline $\mathrm{AGGO} 3$ & 772 & KINGKIGGSN & MQLDPDSIPV & VS----AKD- & IC & PGNVSKDI & PSIAAVVASV & DK-GASKYVT & 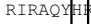 & CE & QNLGD ICK & & & \\
\hline AGO 7 & 98 & KINAKIGGSM & TELYNSIPSH & IPRLLRPDEP & VIFMGADVTH & PHPFDDCS-- & PSVAAVVGSI & NWPEANRYVS & RMRS & $2 E$ & I IQD LDLMVK & & & ELLD \\
\hline HL4 & 764 & KINAKLGGCN & IALYSSEPCQ & IPRIFLSEEP & VMFMGADVTH & PHPLDDSS-- & PSVVAVVASM & NWPSANKY IS & RMRSQI & KE & I IEQLDVMAG & & & -ELLE \\
\hline OsAGO1a & 759 & GGRN & TVLVDALTRR & -I-PLVSDRP & $\mathrm{H}$ & FEDSOS- & PSIAAVVASQ & KYAG & & & 'KVWK & & & \\
\hline $\mathrm{SAGO1b}$ & 796 & KINVKVGGRN & TVLVDALTRR & -I-PLVSDRP & TI IFGADVTH & PHPGEDSS-- & PSIAAVVASQ & DWPEVTKYAG & & $Q E$ & LFKVWQ & & RGTV & LLI \\
\hline & 28 & KINVKVGGRN & TVLVDALSRR & -I-PLVSDRP & TI IFGADVTH & GEDSS-- & IVASQ & DWPEITKYAG & & & FKEWK & & GVV & MI KELLI \\
\hline & 588 & & & & & & & & & & & & & \\
\hline OSAGO1d & 719 & KINVKVGGRN & TVLVDAVSRR & -I-PLVTDRP & TIIFGADVTH & PHPGEDSS-- & PSIAAVVASQ & DWPEVTKYAG & LV & QE & NITH & & $---D H$ & CGGMVRELLI \\
\hline & 75 & KINV & TVLVD & DIP & IIIFGADVTH & NGEF & & KYAG & & & & & $\mathrm{V}$ & I \\
\hline & 664 & K & & & & & & & & & & & & \\
\hline SAGO17 & 564 & KINAKMGGRN & TVLVDALEMR & -L-PHVRDTP & TIVFGAHVTH & PHPGK & SS & DWPEVTKYAG & LI & QE & QD & & -- & TSGMIKEHLM \\
\hline SMEI & 745 & KINVK & TVLERAFIRN & GT $>2>$ & TI IFGADVTH & $\mathrm{P}$ & SS & DWPEITKYRG & & & VGGK & & V & MIRELLI \\
\hline & 9 & KINY & & & SLVL---MSH & & & & & & & & & \\
\hline AtAGO5 & 7 & KINVK & TVLNDAIRRN & -I-PLITDRP & TI IMGADVTH & $\mathrm{PQ}$ & PS & DWPE INKYRG & LV & $\mathrm{EE}$ & VQ & & GLV & HSGLIREHF I \\
\hline & & & TVLE & $-I$ & & & & & & & & & & \\
\hline 014 & 27 & KINV & SVLQRPLVPG & ---GLENT & TI IFGADVTH & PASGE & AS & DWPEI & & $2 E$ & MTE & VP & & $\mathrm{CGC}$ \\
\hline & 593 & KSM & & $-\cdots-$ SVYV & IRQ & & & & & & & & NRLV & YGGMI \\
\hline & & $\mathrm{KIN} z$ & SVE & - & TII & & & DV & & & & & & \\
\hline & 6 & & PA & P & & & & & & & & & & \\
\hline & 8 & $\mathrm{LN}$ & SL. & & TI & & & & & & & & & LL \\
\hline & & & & & & & & & & & & & & \\
\hline & 3 & IN & s & LVSKTP & ILG & & & W & & & & & & \\
\hline & 589 & & SLLG & & TLI & & & & & & & & & DNG \\
\hline & 64 & & SKLSI & 2TP & & & & & & & LD & & & \\
\hline & & & & & & & & & & & & & & \\
\hline
\end{tabular}

1

GSDAOFDMVL NVELLDVKLT -FEK-NGY-- ---NPKITVI VAOKRHOTRF FPATNN---D GSDKGNVPSG TVVDTKVIHP YEYDFYLCSH HGGIGTSKP AHSQAPE-KR PNKIVIFRDG VSDGQFDMVL NVELQNVKDV -FAK-VGY-- --NPQITVI VAQKRHQTRF FPATTSK--D GRAKGNVPSG TVVDTTIIHP FEYDFYLCSQ HGAIGTSKP VFEKRNR-VK PQRIIYFRDG VSDGQFDMVL NEELADMEKA -IKT-KDY-OSAGO3 AYEKVNK-KK PDSIIYFRDG VSDGQFDMVL NEELADMENK -IMV-GDYDFYKAVK-KL PNRIIFERDG VSETQFKKVL QEELQSIKTA -CSKFQDY
EFLKEVG-KL PSRIIFFRDG VSETQFYKVL KEEMHAVRTT -CSRYPGY SFKRATG-QK PQRIIFYRDG VSEGQFYQVL FYELDAIRKA CASLEADY-SFKRATG-QK PQRIIFYRDG VSEGQFYQVL LYELDAIRKA CASLEPNY-AFRRSTG-HK PLRIIFYRDG VSEGQFYQVL LYELDAIRKA CASLEAGY SFKRSTG-EK PQRIIFYRDG VSEGQFYQVL LYELNAIRKA CASLETNY SFKRSTG-QK PQRIIFYRDG VSEGQFYQVL LHELDAIRKA CASLEANY SERKATG-QK PLRIIFYRDG VSEGQFYQVL LYELDAIRKA CASLEPNY SFRKATG-QK PLRIIFYRDG VSEGQFYQVL LYELDAIRKA CASLEPNY SFYRATK-RK PGRIIFYRDG VSKGQLPQAL MHELGAIKMA CASMGPDY AFRKKTG-RR PERIIFYRDG VSEGQFSHVL LHEMDAIRKA CASLEEGY AFRKKTG-RR PERIIFYRDG VSEGQFSRVL LHEMDAIRKA CASLEEGY SFYOETOO PQRIT SFYETG-QK PSRIIFYRDG ISEGQFSQVL LYEMDAIRKA CASLQEGY-SFRKANGSYK QRIITRD VSDGQHLHV LYEMDAIKKA TASLDPAY-SFRKANGSYK PGRIIFYRDG VSEGQF SQVL LSEMDAIRKA CASIEEGY AFRRSSNKRK PEHTITRDG VSESOFNOVL NIEIDOTIEA WKSLYAG-DFYTSSNKRK PEHIIIFRDG VSESQFNQVL NIELDQIIEA CKLLDAN-DFYYSSENRK PEHIIIFRDG VSESQFNQVL NIELDQMMQA CKFLDDT--DFYTSTGKRK PDQVIIFRDG VSESQFTQVL NIELDQIIEA CKFLDEN---
DFYTSSGKRK PDHVIVFRDG VSESOFTOVI NIELDOIIEA CKFIDEK-EFYRTSRARK PKQIIIFRDG VSESQFEQVL KIEVDQIIKA YQRLGES-DPTITI VAKKRHHTRL FPKDLNQ--Q QTKNGNVLPG TVVDTGVVDP AAYDFYLCSH NGLIGTSRP
- PKITVI VAKKRHHTRL FPKDRNQ--R QTKNGNVLPG TVVDTDVVDP TAYDFYLCSH KGEVGTSRP -NPSITEA VVQKRHHTRL FRCDP----- --DHENIPPG TVVDTVITHP KEFDFYLCSH LGVKGTSRP KPLITEI VVQKRHHTRL FHRERNGSSS HYSDQNIPPG TVVDTVITHP REFDFYLCSH WGTKGTSRPT QPPVTFV VVQKRHHTRL FANNHKDQRT VDRSGNILPG TVVDSKICHP TEFDFYLCSH AGIQGTSRPA QPPVTFV VVQKRHHTRL FANNHNDQRT VDRSGNILPG TVVDSKICHP TEFDEYLCSH AGIQGTSRPA QPPVTFV VVQKRHHTRL FAQNHNDRHS VDRSGNILPG TVVDSKICHP TEFDFYLCSH AGIQGTSRPA QPKVTFI VVQKRHHTRL FAHNHNDQNS VDRSGNILPG TVVDSKICHP TEFDFYLCSH AGIKGTSRPA QPQVTEI VVQKRHHTRL FAHNHNDQNS VDRSGNILPG TVVDSKICHP TEFDFFLCSH AGIKGTSRPA QPPVTFI VVQKRHHTRL FANNHRDKNS TDRSGNILPG TVVDTKICHP TEFDFYLCSH AGIQGTSRPA QPPVTFV VVQKRHHTRL FANNHKDRSS TDKSGNILPG TVVDSKICHP SEFDFYLCSH AGIQGTSRPA 作 作 LPPVTFV VVQKRHHTRL FPEVHGRRDM TDKSGNILPG TVKDRQICHP TEFYFYLCSH AGIQGTSRP

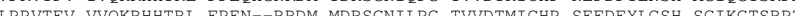
LPPVIF V

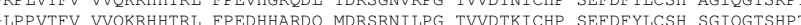
TPRITFI VVQKRHHTRL FPNNYNDPRG MDGTGNVRPG TVVDTVICHP REFDFFLCSO AGIKGTSRPS -WNPKFLLI VAOKNHHTKF FOPTSPE---WNPKF LLL VAQKNHHTKF FQPTSPE------NVPPG TIIDNKICHP KNNDFYLCAH AGMIGTTRP WHPKT VARNHTKF FQSRGPD--- ----NVPPG TIIDSQICHP RNFDFYLCAH AGMIGTTRP -WSPKFTVI VAOKNHHTKF FOSGSPD--- ----NVPPG TVVDKAVCHP RNNDFYMCAH AGMIGTTRP DVPKFTVI VAOKNHHTKL FOAKGPE--- ----NVPAG TVVDTKIVHP TNYDFYMCAH AGKIGTSRPA

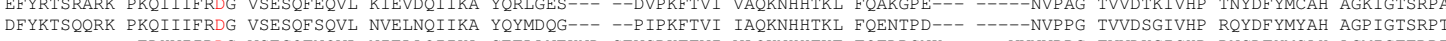

AtAGO2 HYYTLWDELG FTSDQVQKLI FEMCETFTRC TKPVSLVPPV YYADMVAFRG RMYHEASSRE 970 HYYVLSDEIG FNSNOIOKLI FDLCFTFTRC TKPVALVPPV SYADKAASRG RVYYEASLMK 1150 HYYSLLDEHG FASDDLQKLV YNLCFVFARC TKPVSLATPV YYADLAAYRG RLYYE----- 989 OSAGO3 HYSLLDEHG FASDDLQKLV YNLCFVFARC TKPVSLATPV YYADLAAYRG RLYYE---- 102 AtAGO7 HYHILWDENE FTSDELQRLV YNLCYTFVRC TKPISIVPPA YYAHLAAYRG RLYIERSS-- 953 SHL4

OSAGO1a

OSAGO1b HYHVLWDENN FTADALQILT NNLCYTYARC TRSVSIVPPA YYAHLAAFRA RFYME----- 959 $\begin{array}{llll}\text { HYHVLWDENN FTADALQTLT NNLCYTYARC } & \text { TRSVSIVPPA } & \text { YYAHLAAFRA RFYME----- } & 990 \\ \text { HYHVLWDENN FTADGIQSLT NNLCYTYARC } & \text { TRSVSIVPPA YYAHLAAFRA RFYLEPEIMQ } & 951\end{array}$ HYHVLWDENN FTADEMQTLT NNLCYTYARC TRSVSVVPPA YYAHLAAFRA RFYME----- 935 YYHUWEND FLAGSF QLLT NYCYTSATC TQSISUVAPV HYARLLSSRA RYYKHYHVLYDENH FTADELQTLT NNLCYIYARC THAVSVVPP- - HYHVLLDENG FTADQLQMLT NNLCYTYARC TKSVSIVPPA YYAHLAAFRA RYYMESEMSD 963 HYHVLLDENG FKADTLQTLT YNLSYTYARC TRAVSIVPPA YYAHLGAFRA RYYME----- 939 HYHVLHDENR FSADQLQMLT YNLCYTYARC TRSVSVVPPA YYAHLAAFRA RYYDE----- 1009 $\begin{array}{lll}\text { HYYVLEDENN FSADALQTLT YHLCYTYARC TRSVSIVPPV YYAHLAASRA RHYLE----- } & 850 \\ \text { HYHVLRDDNN FTADQLQSVT NNLCYLYTSC TRSVSIPPPV YYAHKLAFRA RFYL------ } 1055\end{array}$ HYHVLYDEIG FSADELQELV HSLSYVYQRS TSAISVVAPI CYAHLAAAQL GTFMKFEDQS 890 HYHVLYDEIG FATDDLQELV HSLSYVYQRS TTAISVVAPV CYAHLAAAQM GTVMKYEELS 862 HYHILHDEIG FSADDLQELV HSLSYVYQRS TTAISVVAPI CYAHLAAAQV SOEIK----- 870 HYHVLHDEIG FSPDDLQELV HSLSYVYQRS TTAISVVAPI CYAHLAAAQV GTFLK----- 872 $\begin{array}{lll}\text { HYHVLLDEIG FSPDDLQNLI HSLSYVNQRS TTATSIVAPV RYAHLAAAQV AQFTKFEGIS } & 856 \\ \text { HYHVLLDEIG FLPDDVOKLV LSLSYVYORS TTAISVVAPI CYAHLAAAOM GOFMKFEFFA } & 329\end{array}$ HYHVLHDENN FTPDDLQELV HNLSYVYQRS TTAISGVAPI CYAHLAAAQV SQF------ 2195

\section{Figure I}

Amino acid alignment of Piwi domains of rice and Arabidopsis AGO proteins. The protein sequences were aligned using clustalX (I.83). The conserved Asp, Asp and His (DDH) triad residues are marked with downward arrows, while the His $(\mathrm{H})$ corresponding to $\mathrm{H} 798$ of Arabidopsis AGOI have been boxed. Amino acid positions corresponding to the beginning and end of the Piwi domains in each protein are mentioned. 


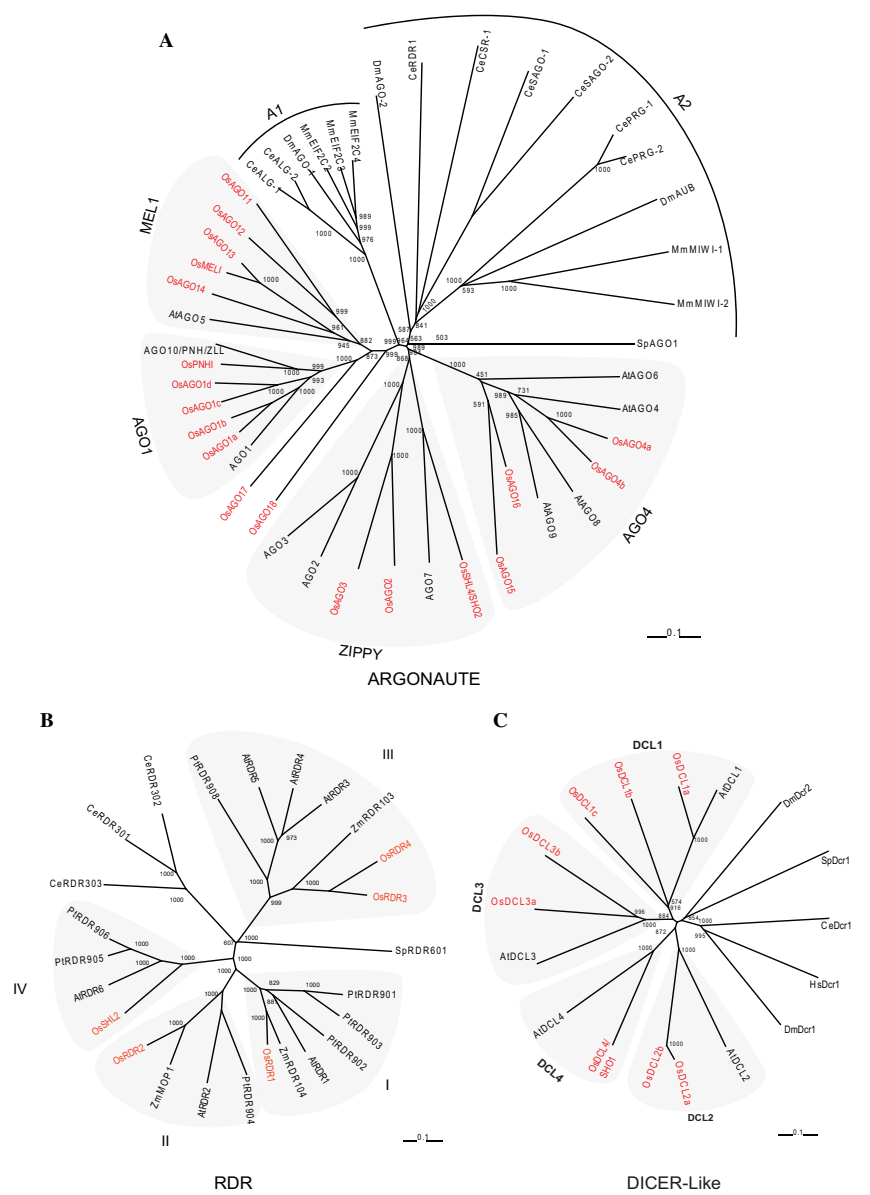

Figure 2

Phylogenetic analysis of Dicer-like, Argonaute and RDR genes of rice with other organisms. A. Argonautes. Unrooted, neighbor joining tree was constructed by alignment of total protein sequences from rice, Arabidopsis, $C$. elegans, yeast, Drosophila and humans. Four subgroups are marked, AGOI, MELI, ZIPPY and AGO4 as described by Nonomura et al., (2007, [15]). Plant-specific clades are shaded and rice Argonautes have been highlighted in red in each group. Accession numbers of sequences are as follows: CeALG-I (NP5 I0322), CeALG-2 (NP493837), CePRG-I(CAA98I I 3), CePRG-2 (AAB37734), CeRDE-I (AAF06 I59), DmAGOI(NP523734), DmAGO2 (AAF496 I9), DmAUB (CAA64320), MmMIWII(NP067286), MmMIWI2 (AYI35692), MmEIF2C2 (NP6948I8), MmEIF2C3 (NP70045I), MmEIF2C4 (NP6948I7), SpAGOI (CAAI 9275), CeCSR-I (NP00I040938), CeSAGO-I (NP5046I0), and CeSAGO-2 (NP490758), AtAGOI0 (AAD40098), AtAGOI (AACI8440), AtAGO7 (AAQ92355) and AtAGO4 (NP_565633), AtAGO2 (Locus:2197545), AtAGO3 (Locus:2 197550), AtAGO6 (Locus:2059370), AtAGO8 (Locus:2 I47072) and AtAGO9 (Locus:2 I79008). B. RNAdependent RNA polymerase. Analysis of evolutionary relatedness between rice, Arabidopsis, Maize, Populus, yeast and $C$. elegans RDR genes using full length RDR protein sequences. The protein sequences of all RDRs except rice were obtained from the Chromatin database, ChromDB http://www.chromdb.org. Plant-specifc clades have been shaded. The Arabidopsis proteins are AtRDRI(Atlgl4790), AtRDR2 (At4gl I I30), AtRDR3 (At2gl 99l0), AtRDR4 (At2gl 9920), AtRDR5(At2gl9930), and AtRDR6 (At3g49500). PtRDR90I through PtRDR906 and PtRDR908 are Populus trichocarpa proteins, ZmRDR I03, ZmRDR I04 and ZmMOPI are Zea mays RDR proteins, SpRDR60I is from Schizosaccharomyces pombe and CeRDR30I-CeRDR303 are from Caenorhabditis elegans. C. Dicer-like proteins. Neighbour-joining tree was constructed after alignment of total protein sequences of rice and Arabidopsis. Protein sequences from Drosophila, humans, yeast and $C$. elegans were included as outgroups. Plant-specific clades have been shaded. Protein sequences were downloaded from National Center for Biotechnology Information (NCBI). Accession numbers and abbreviations are as follows: HsDcrl, Homo sapiens Dicer-I (NP_085I24); DmDcr I, Drosophila melanogaster, Dicer-I (NP_524453); DmDcr2, Drosophila melanogaster Dicer-2 (NP_523778) CeDcr I, Caenorhabditis elegans, Dcr-I (AAA28I0I); SpDcr I, Schizosaccaromyces pombe, Dcr-I (Q09884); AtDCLI, Arabidopsis thaliana DCLI, (NP_171612); AtDCL2, Arabidopsis thaliana DCL2, (NP_566199), AtDCL3, Arabidopsis thaliana DCL3, (NP_189978); AtDCL4, Arabidopsis thaliana DCL4, (NP_197532). Rice Dicer-like proteins are shown as OsDCLIa to OsSHOI/DCL4. Scale bar in each panel represents 0.1 amino acid substitution per site. 
Zea mays and Saccharum officinarum (AZM5_100042, CA252311) but not in Arabidopsis, thereby suggesting that duplication of OsDCL1 may have occurred after the divergence of monocots and dicots ( $60 \mathrm{my}$ ).

A gene pair was considered tandemly duplicated if the members were separated by less than five intervening genes and shared $\geq 40 \%$ sequence similarity at amino acid level. Three OsAGO gene pairs, (OsAGO4a-15; OsAGO2-3 and OsAGO11-12) localized close to each other on chromosomes 1, 4 and 3, respectively, thus are considered to have arisen due to tandem duplications (Figure 3). They share 55\%,54\% and 51\% identity at amino acid level between the pair partners. None of the OsDCLs or OsRDRs seems to have undergone tandem duplications.

\section{Transcript profiling of genes during vegetative and reproductive development and abiotic stress}

To analyze transcript abundance of Dicer-like, Argonaute and RDR genes at different stages of reproductive development in rice, microarray datasets generated in-house were utilized. The stages of vegetative and reproductive development analyzed in the present study are summarized [see Additional file 1]. Microarray hybridization was performed using the 57K Affymetrix GeneChip ${ }^{\oplus}$ Rice Genome Arrays as described previously [27]. Normalization of data was done using GCRMA algorithm and was $\log _{2}$ transformed before differential expression analyses were undertaken. In the microarray dataset, $>99.9 \%$ of negative controls and non-rice probe-sets were found to have average signal intensity values less than 15 . Therefore, the value '15' was considered as the cut off value to distinguish between expressed and non-expressed genes in a particular tissue/developmental stage.

The rice DCL genes OsDCL1a, OsDCL2, OsDCL3a and SHO1 were found to express ubiquitously (minimum normalized signal intensity values $67.7,290.5,32.0$ and 82.2 , respectively) in the tissues/stages of plant development analyzed [see Additional file 2]. These genes expressed at moderate to high levels in vegetative tissues but their expression was markedly reduced during specific stages of reproductive development (Figure 4A). Specifically, SHO1, OsDCL1a and OsDCL2 showed an approximately 10-, 37- and 10-fold down-regulation in late seed development stages (S4 and S5) in comparison to their peak expression in young seedlings, Y-leaf and SAM, respectively [see Additional file 3]. In contrast, two of the low expressing genes, OsDCL1b and OsDCL3b, exhibited panicle- and early seed-specific expression. The peak expression of OsDCL1b was found to be in P6 stage (corresponding to mature pollen stage of anther development) and was $\sim 3$-fold higher than its average signal intensity values in vegetative tissues. OsDCL3b expressed at 6.5-fold higher levels in P1-II stage in comparison to its expression in vegetative stages. In vegetative tissues (except SAM), the average signal intensity values for both these genes were less than 15. Like OsDCL1a, OsDCL2, OsDCL3a and SHO, three Arabidopsis genes, AtDCL1, AtDCL2 and AtDCL4, were found to express in all the tissues/stages of development. On the other hand, AtDCL3 (like OsDCL3b) exhibited specific up-regulation of expression in reproductive stages, while in vegetative stages its expression was barely detectable. None of the OsDCL genes showed alteration in expression in response to the three abiotic stress conditions, viz. cold, salt or dehydration (Figure 4A).

Among OsAGOs, 11 out of 19 genes (OsAGO1a, 1b, 1c, $1 \mathrm{~d}, 2,4 \mathrm{a}, 4 \mathrm{~b}, 13,17,18$ and OsPNH1) were found to express in both vegetative and reproductive tissues (Average signal intensities > 62.6; Figure 4B) [see Additional file 2]. Out of 19 genes, 14 genes belonging to AGO1, AGO4 and MEL1 clades (OsAGO4b, 1b, 4a, 2, 1a, 1d, 16, 1c, OsPNH1, OsMEL1, 13 and SHL4), were significantly upregulated (7-, 10-, 7-, 2.3-, 18-, 2-, 8-, 8-, 36-, 12-,11- and 36-fold, respectively) at the onset of floral development. Average signal intensity values of MEL1 clade genes, OsAGO13 and OsMEL1, were $<15$ in vegetative tissues as compared to the other genes of AGO1 and AGO4 clades. Arabidopsis AGO5 has been shown to express only in reproductive tissues, i.e. during all stages of flower and seed formation [29]. This expression pattern is similar to that of OsMEL1 in rice. However, the expression of closely related OsAGO13 and OsAGO14 overlapped with that of OsMEL1. Individually, OsAGO13 expressed significantly in SAM and early stages of floral initiation (P1-I, P1-II and P1-III) and OsAGO14 expressed in late panicle and early seed development stages (Figure 4B). OsMEL1 and OsAGO14 share $60 \%$ identity at amino acid level and lie in duplicated segments of chromosomes 3 and 7 (Figure 3). However, their contrasting expression patterns during reproductive development suggest that these two genes have significantly diverged functionally after the duplication event (Figure 5). For the tandemly duplicated pair, OsAGO11 and OsAGO12, in this clade, only OsAGO12 transcripts could be detected during late panicle (P6) and early seed stages (S1-S4) while transcripts for OsAGO11 were barely detectable at any of the stages (Figure 5). In AGO1 subgroup, there are 5 rice genes clustered with two Arabidopsis genes, AGO1 and AGO10. Unlike their rice counterparts, Arabidopsis AGO1 and AGO10 expressed in vegetative as well as reproductive tissues without any significant increase in transcript accumulation in reproductive tissues. Whereas, all the rice genes in this subgroup exhibited 3- to 36-fold enhancement in transcript levels coinciding with the initiation of reproductive development. Expression pattern of the segmentally duplicated genes, OsAGO1a and OsAGO1b, in this clade overlapped at all stages and in all tissues, with OsAGO1b being 


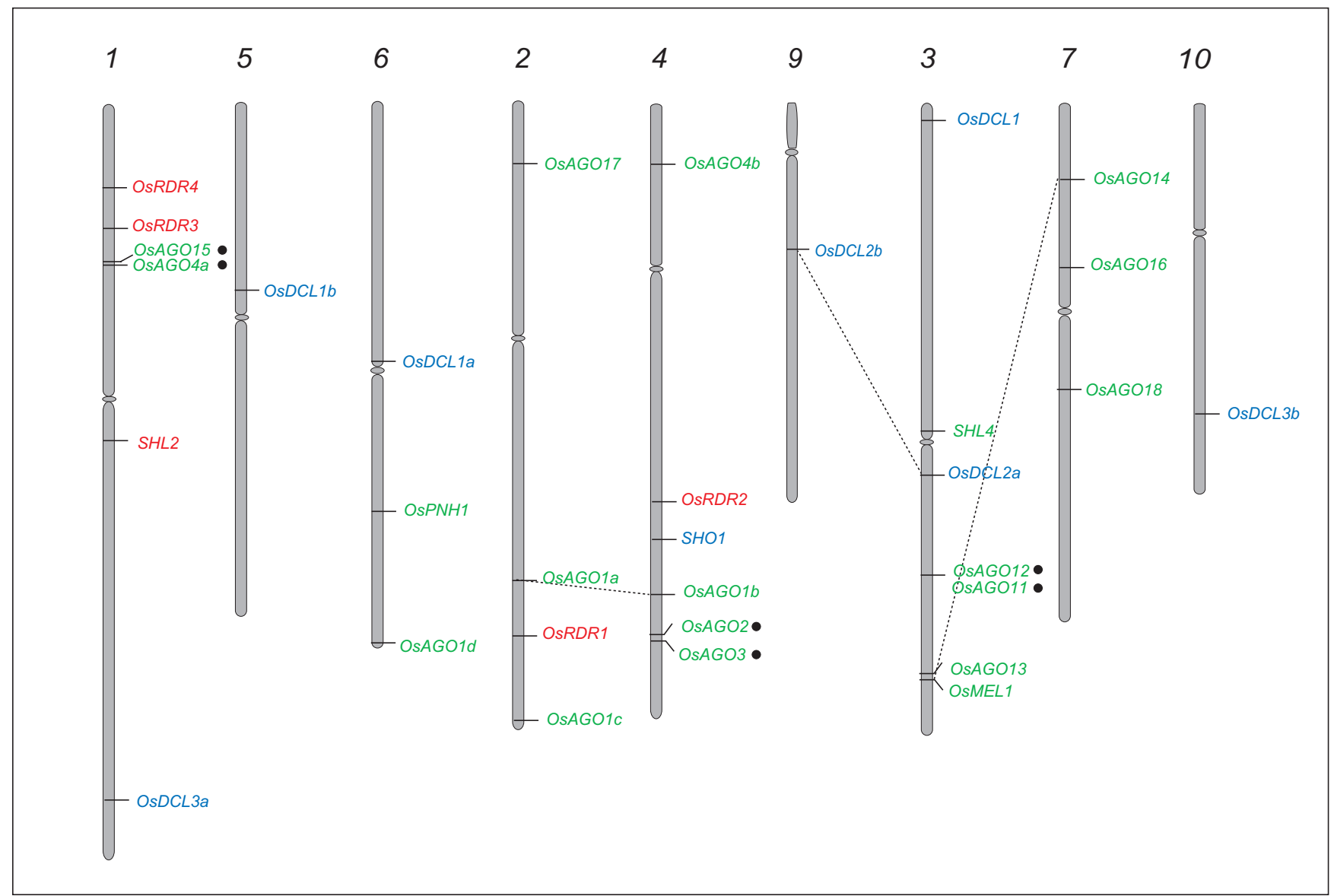

\section{Figure 3}

Chromosomal localization of rice DCL, Argonaute and RDR genes. Numbers on top designate the chromosome number for pseudomolecules. Segmentally duplicated genes have been joined using dashed lines, while tandem duplications are indicated by filled circles.

expressed at relatively higher levels than OsAGO1a (Figures $4 \mathrm{~B}$ and 5). In the ZIPPY clade, expression of tandemly duplicated genes, OsAGO2 and OsAGO3, overlapped only during P3-P5 stage of panicle development while at all the other stages, only OsAGO2 was observed to be highly expressed while, OsAGO3 transcripts could not be detected (Figure 4 and 5). This shows that both segmental and tandem duplication of Argonaute genes have resulted in formation of gene partners that have probably diverged functionally during the course of evolution and have thus contributed to the diversity of this protein family in rice. Members of ZIPPY subgroup, SHL4/SHO2 and AGO7 differed from other members of this clade in being expressed predominantly during early stage of floral development. There are four genes each from rice and Arabidopsis that constitute the AGO4 clade. Out of these, the coding region of OsAGO15 is interrupted by a retrotransposon. Amongst the Arabidopsis genes, expression profiles of only AGO4 and AGO9 could be obtained. On the basis of transcript accumulation patterns and sequence similarities, the Arabidopsis AGO4 seems to have two counter- parts in rice, OsAGO4a and OsAGO4b. These three genes showed enhanced expression during early stages of floral development. The OsAGO4a and OsAGO4b were up-regulated by 6.9 and 6.7 folds, while the enhancement was only 2.6 folds in case of AtAGO4 (Figure 4B) [see Additional files 3 and 4]. Conservation in expression profiles was also observed for Arabidopsis AGO2 and OsAGO2 genes, whereas, the expression of AGO3 gene differed in both rice and Arabidopsis. AtAGO3 expressed specifically during stages of seed development, while expression of OsAGO3 was confined to later stages of panicle formation (P3-P5). OsAGO18, that did not cluster into any of the four subgroups exhibited high level expression during late panicle (P3-P6) and seed development stages, S1-S5, along with low level expression in vegetative tissues. For OsAGO11, a unique Affymetrix probe set ID existed, but no transcripts could be detected in any of the tissues or developmental stages analyzed. Most OsAGOs did not show any variation in expression in response to the three abiotic stresses, except OsAGO2, whose transcript levels 


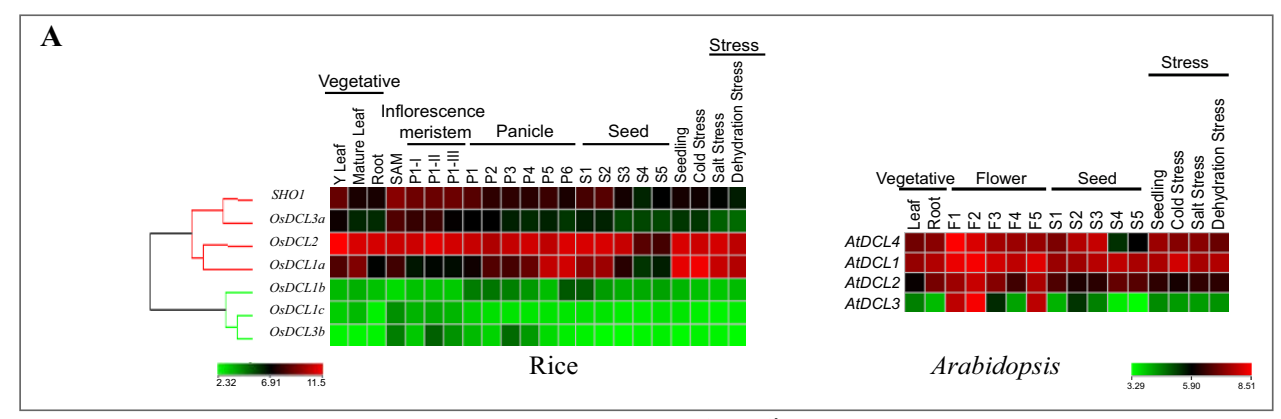

Dicer-Like

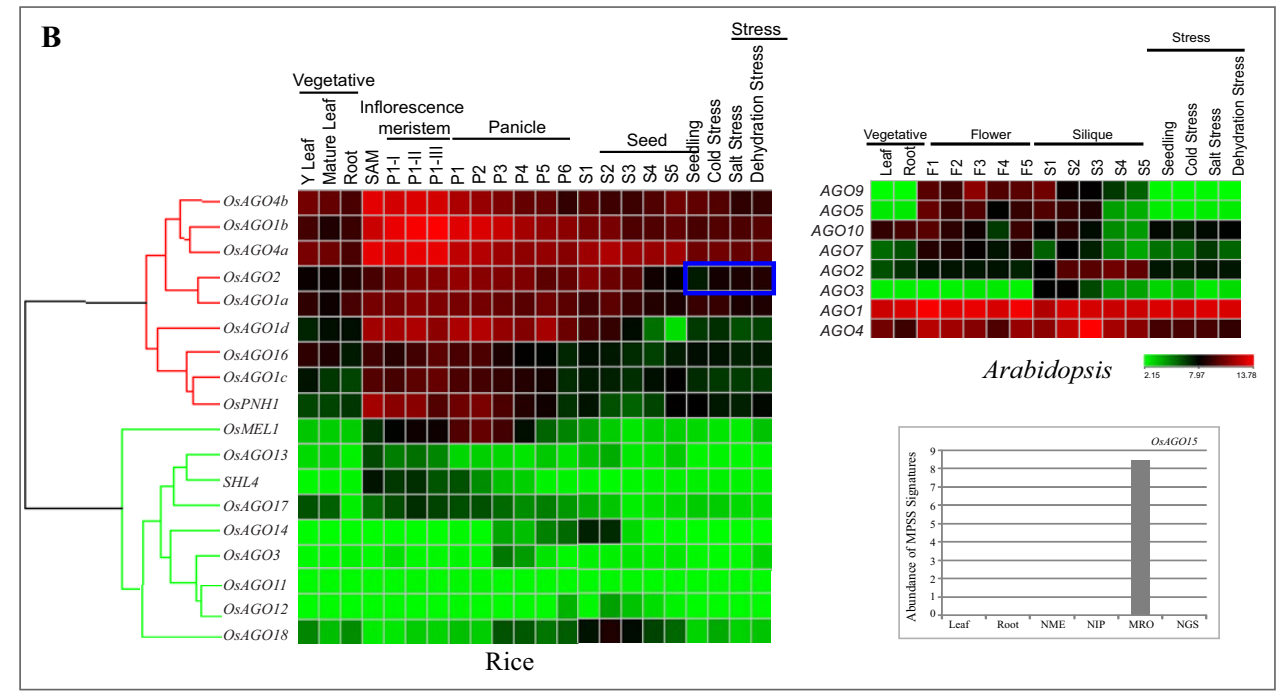

Argonautes

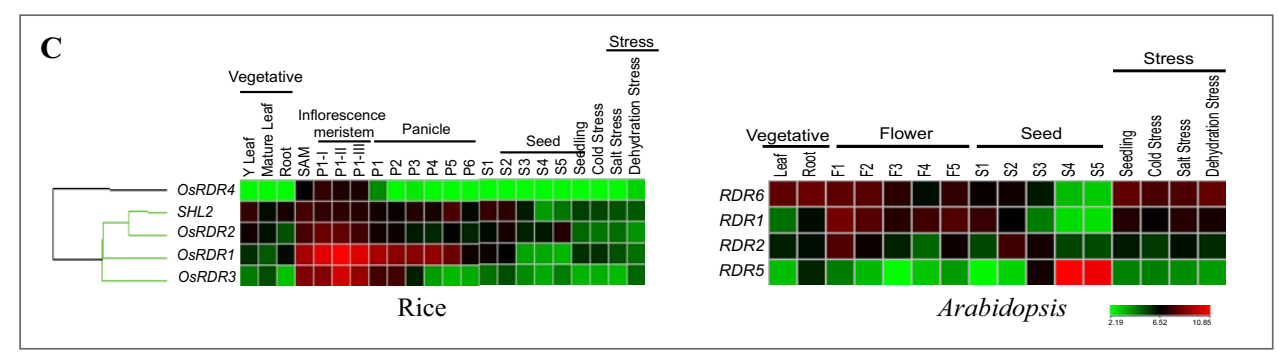

RNA-dependent RNA Polymerases

\section{Figure 4}

Microarray based expression analysis of Dicer-like, Argonaute and RDR genes of rice and Arabidopsis. For rice genes the expression profiles have been analyzed in vegetative tissues ( $Y$ leaf, mature leaf, roots), Shoot Apical Meristem (SAM) and six stages of panicle development (PI to P6) along with 3 substages of PI i.e. PI-I, PI-II and PI-III, five stages of seed development (SI to S5) and under three abiotic stress conditions (cold, salt and dehydration). For Arabidopsis, expression profiles of two vegetative stages (leaf and root), five stages of flower development (FI-F5), five stages of silique development and three stress treatments (cold, salt and dehydration) have been compiled. The color bar in each panel represents $\log _{2}$ expression values. Developmental stages used for expression profiling are mentioned on top of each column. Panicle and seed stages have been listed in the temporal order of development. On the left side of expression map, cluster dendrogram is shown. The bar graph in panel B shows the expression profiles of OsAGOI5 based on MPSS data [4I] from 60-days mature leaf, 60-days mature root, 60-days crown meristematic tissue (NME), 90-days immature panicle (NIP), mature reproductive organs (MRO) and 3days germinating seed (NGS). Expression of OsAGO2 that shows two-fold up-regulation in response to all three stresses is boxed in blue in panel $\mathrm{B}$. 
increased by $>2$-folds ( -value $\leq 0.05$ ) in response to all three stresses.

Of the five OsRDR genes, four expressed both in vegetative and floral tissues with average intensity values of $>15$ in any or all stages of vegetative, floral- and seed-development (Figure 4C). However, a significant increase in the transcript abundance for OsRDR1, OsRDR2 and OsRDR3 (56-, 4.2- and 26.6-fold, respectively, at p-value $\leq 0.05$ ) was observed during stages of early panicle development (P1-I to P1-III) in comparison to their expression in mature leaves (Figure 4C) [see Additional files 3 and 4]. The expression of OsRDR1 was detectable up to S2 stage of seed formation and declined thereafter. The expression profile of the closely related Arabidopsis genes, RDR1 and $R D R 2$, did not show significant increase in transcript levels as compared to rice genes during early flower development; nevertheless, their transcripts were detectable until early stages of seed development. Unlike any other corresponding gene in Arabidopsis, the expression of OsRDR4 (that did not show any detectable expression in vegetative tissues except SAM) was found to be up-regulated by 36 folds in early stages of panicle development in comparison to mature vegetative tissues.

Four genes, OsAGO14, OsRDR3, OsRDR4 and OsDCL3a, showing discrete expression patterns were selected for validation of microarray expression profiles by QPCR analysis. Figure 6 shows a comparison of the QPCR and microarray analysis. The expression patterns obtained for all four genes using QPCR were similar to that derived from the microarrays with Pearson's correlation values ranging from 0.86 to 0.94 (Figure 6).

\section{Discussion}

RNA interference plays an important role in regulating gene expression at post transcriptional level during vegetative and reproductive development in plants [6]. This process is mediated by concerted activities of proteins like, Dicers, Argonautes and RNA-dependent RNA polymerases. In the present investigation, we have identified the genes encoding these proteins families in rice and studied their distribution on rice chromosome pseudomolecules. Phylogenetic analysis has shed light on the evolution of members in each gene family in rice and has provided insight into multiplicity of Argonaute genes in rice. Microarray based expression analysis at different stages of reproductive development in rice plants was attempted with the view to understand the contribution and developmental timings of activity of these proteins.

\section{Rice Dicer-like genes}

While there is only one Dicer in mammals and nematodes that is involved in processing all sizes of small RNAs, four DCL genes found in Arabidopsis seem to have specialized in the type of small RNAs they process [10]. For example, DCL1 and DCL4 are required for biogenesis of $21 \mathrm{nt}$ small RNAs that correspond mainly to miRNA and tasiRNA, DCL2 affects accumulation of $21 \mathrm{nt}$ RNA that protects against viral infection and DCL3 acts to produce the $24 \mathrm{nt}$ RNAs that mediate de novo DNA methylation, gene silencing and chromatin modification $[19,30]$. We have identified all four classes of $D C L$ genes in rice, that total eight in number. While duplication of DCL2 genes (OsDCL2 $a$ and OsDCL2b), which share more than $90 \%$ similarity at the amino acid level, has also been reported in Arabidopsis and Populus trichocarpa. However, duplication of DCL3 that gave rise to OsDCL3a and OsDCL3b is considered specific to monocots and predates the divergence of rice and maize [10]. In the present study, microarray based expression pattern analysis of rice and Arabidopsis DCL genes at different stages of reproductive development shows conservation in expression pattern of genes in dicot and monocot plants, however, duplication events in rice may also have given rise to genes with novel expression (and probably functional) profiles.

Null mutants of AtDCL1 exhibit pleiotropic developmental defects and are lethal due to loss of accumulation of miRNAs. Henderson et al. (2006) also demonstrated that miRNAs dominate the pool of small RNAs (67.5\%) accumulated in $\mathrm{dcl} / \mathrm{dcl} / \mathrm{dcl} 4$ triple mutants [19]. In rice too, it has been shown that loss-of-function of OsDCL1 but not OsDCL4 affects processing of miRNA [25]. Consistent with the roles of miRNAs in regulation of various plant developmental processes, AtDCL1 was found to express ubiquitously in all tissues. The presence of three DCL1 like genes in rice with divergent expression profiles is suggestive of diversification of DCL1 function in rice.

AtDCL3 together with RDR2 in Arabidopsis is known to affect accumulation of small RNAs that mediate de novo DNA methylation and transgene silencing. In rice, of the two OsDCL3s, OsDCL3a was previously considered as the functional counterpart of AtDCL3 on the basis of overall homology and conservation of $\mathrm{dsRBb}$ domain. On the other hand, the dsRBb domain in OsDCL3b was so divergent from that of AtDCL3 that it was suggested to categorize it as an altogether different, fifth class of dicer-like protein [10]. AtDCL3 and OsDCL3b show low level expression in vegetative tissues with enhanced transcript accumulation in floral tissues and early stages of seed development. However, OsDCL3b expression was confined only to early (pre-meiotic) stages of panicle development. Hence, on the basis of expression profiles $A t D C L 3$ and OsDCL3b share similar expression domains, although the encoded proteins possess highly divergent dsRBb domains and could therefore be interacting with different RNA substrates. 
Tandem Duplications

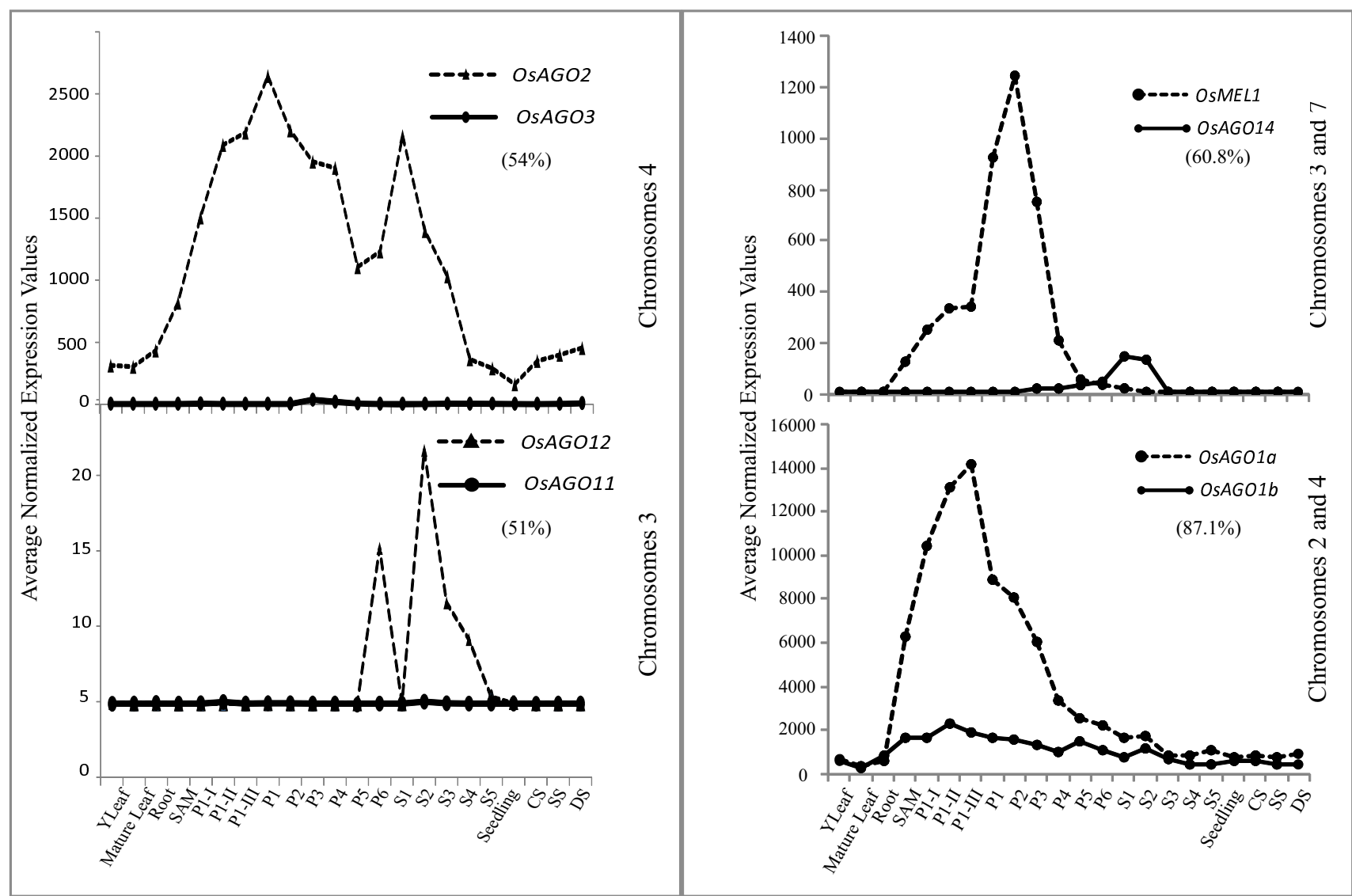

Figure 5

Comparison of expression profiles of tandemly and segmentally duplicated Argonaute genes in rice. $Y$-axis represents the average normalized expression values obtained from microarray analysis, while the $X$-axis depicts tissues/developmental stages [see Additional file I]. Chromosomal location of each gene is mentioned on the right. Percentages in brackets indicate percentage of identical residues in the encoded proteins.

Arabidopsis DCL4 has been shown to function redundantly with DCL2 and DCL3 to process SHL2(OsRDR6) generated double stranded RNA into tasiRNA The RNA template for SHL2 is in turn produced by the activity of miR173 and miR390 generated by DCL1, HYL1, HEN1 and AGO1 [30]. The expression patterns of rice genes, OsDCL4, SHL2 and OsAGO1 members (OsAGO1a, OsAGO1b, OsAGO1c and OsAGO1d) matched that of the corresponding genes in Arabidopsis especially in exhibiting enhanced expression during early stages of floral/panicle development. This further suggests that the diversification in function, as speculated from their expression pattern, of most plant DCL genes may have occurred after the split of plants and animal lineages but before the divergence of monocots and dicots.
Multiple AGOs and their roles in rice plant development Argonautes form an evolutionarily conserved gene family whose members are present in both single celled and multicellular eukaryotes. Multiple genes have been reported in various organisms. Rice has the largest number of Argonautes among plants, almost double the number reported in Arabidopsis and second only to C. elegans that possesses 27 AGOs [14]. Rice genes with similar/overlapping expression domains with Arabidopsis AGO1, (OsAGO1a, OsAGO1b, OsAGO1c and OsAGO1d) AGO5, (OsAGO13, OsAGO14 and OsMEL), and AGO4, (OsAGO4a and OsAGO4b), have been identified in the present study. Most of these genes appear to have evolved by duplication events (tandem or segmental) followed by differentiation of expression patterns. These duplication events may also have given rise to redundancy among OsAGO genes as is evident from the overlapping expres- 
sion profiles of OsAGO1a, OsAGO1b, OsAGO1c and OsAGO1d and OsAGO4a and OsAGO4b genes. On the other hand, OsMEL1 and OsAGO14, that appear to have arisen by duplication of segments in chromosomes 3 and 7 , exhibit contrasting expression profiles during panicle and seed development.

Argonautes are highly basic RNA binding proteins characterized by presence of PAZ and PIWI domains. The PIWI domain adopts an RNAse-like fold and has predicted endonuclease activity (slicer). It binds to 5 ' end and also interacts with the target RNA $[31,32]$. The PAZ domain interacts with 3 ' of small RNAs and is the candidate region that determines the specificity of Argonautes. Consistent with this, homology among various rice AGOs was observed to be minimum in the PAZ regions ( $21 \%$ ) while their PIWI domains exhibited more than $90 \%$ conservation of amino acids. The endonuclease property of AGO proteins involved in RNAi resides in the PIWI domain that possesses three conserved metal-chelating amino acids (DDH). Subfamilies of AGO proteins, primary and secondary Argonautes, have been described in C. elegans on the basis of presence or absence of these catalytic amino acid residues [14]. Five of the Arabidopsis AGO proteins, AGO2, AGO3, AGO4, AGO6 and AGO9 lack either the critical DDH or the $\mathrm{H} 798$ residue. In rice too, eleven genes do not code for the conserved catalytic residues in their PIWI domains. Of these, OsAGO3, OsAGO5a, OsAGO5b and OsAGO15, are expressed specifically or preferentially in reproductive tissues. Absence of catalytic amino acids could inhibit the processing of target RNA by endonucleolytic cleavage in these proteins. These proteins could, therefore, require accessory factors for mediating mRNA turnover. However, it has been reported that an aspartate at the third position of the catalytic triad in related RNase proteins, Integrase and Tn5, can chelate the divalent metal ions as efficiently as histidine residue and restore the catalytic activity [32,33]. Accordingly, AGO2 and AGO3 of rice and Arabidopsis that possess DDD could still function as slicer components of silencing effector complexes. In rice, while OsAGO2 is ubiquitously expressed, OsAGO3 along with OsAGO14, OsAGO13 and OsMEL1 are expressed specifically in reproductive tissues. These genes can, therefore, be considered as candidate genes regulating expression of endogenous genes via RNA interference that may or may not involve cleavage of target RNA as their mode of activity.

In rice, knockout studies by three groups have provided insights into the functions of three OsAGO genes, OsMEL1, SHL4/SHO2 and OsPNH1 [15,26,34]. OsMEL1 is a unique AGO protein that regulates meiosis in germ cells and proper development of male and female gametes by chromatin modification probably mediated by H3K9 methylation. Whether OsMEL1 directly interacts with regulatory small RNAs to bring about desired changes at the chromatin is not yet known. OsMEL1 also has a duplicated partner, OsAGO14, located on chromosome 7 that does not show any expression in vegetative tissues and is specifically expressed at stages beginning from P3 in panicles and until S2 stage in seeds. Furthermore, diversity in their PAZ domains suggests that these two proteins could interact with different classes of small RNAs, while retaining the mode of processing the target RNA by virtue of the catalytic DDH motif in their PIWI domains.

The rice SHL4, SHL2 and SHO1 genes have been shown to be involved in initiation and formation of SAM during rice embryogenesis. This is mediated by miRNA and tasiRNA regulation of homeodomain-leucine zipper (HDZIPIII) and ETT/ARF gene families [26]. OsPNH1, is the third gene whose functional analysis revealed that it affects the development of SAM and leaf development [34]. This gene is closely related to OsAGO1.

\section{Rice $R D R$ genes in panicle development}

RNA-dependent RNA polymerases are the regulatory components of RNAi machinery, which enhance the potency of RNAi by amplifying the aberrant RNA population [35]. These proteins are required for both cytoplasmic gene silencing that is triggered by transgenes or viral infection, as well as, nuclear gene silencing for transposons and inverted repeats in the genome. In Arabidopsis, 6 genes encode RDRs out of which only 3 genes have been shown to be involved in viral defense, chromatin silencing and PTGS. RDR6, also known as SGS2 and SDE1 amplifies improper terminated and unpolyadenylated RNAs generated from transgenes or inverted repeats to trigger degradation of complementary RNA species [36]. Genetic studies in Arabidopsis have also revealed that RDR6 functions in the same pathway as AGO7 and Asymmetric leaves 1 and 2 (AS1 and AS2) to control adaxial/abaxial patterning in leaves [37]. This role of RDR6 appears to be evolutionarily conserved in dicot and monocot lineages as in rice it was recently reported that SHL2 along with SHL4, and SHO1 affect siRNA and tasiRNA mediated regulation of endogenous genes involved in SAM and leaf development [26]. Arabidopsis RDR2 is required for combating viral infection through PTGS and is involved in siRNA mediated de novo methylation of direct repeats. Recently, it has been shown that the homolog of Arabidopsis RDR2 in maize, MOP1, is involved in paramutation of b1 locus [38]. The MOP1 gene maintains a threshold level of RNA encoded by repeat sequences that modify chromatin at b1 locus. This gene is also closely related to OsRDR2. The role of OsRDR2 is not known yet, however its expression was observed to overlap with Arabidopsis RDR2 at earlier stages of flower development and it phylogenetically relates to 


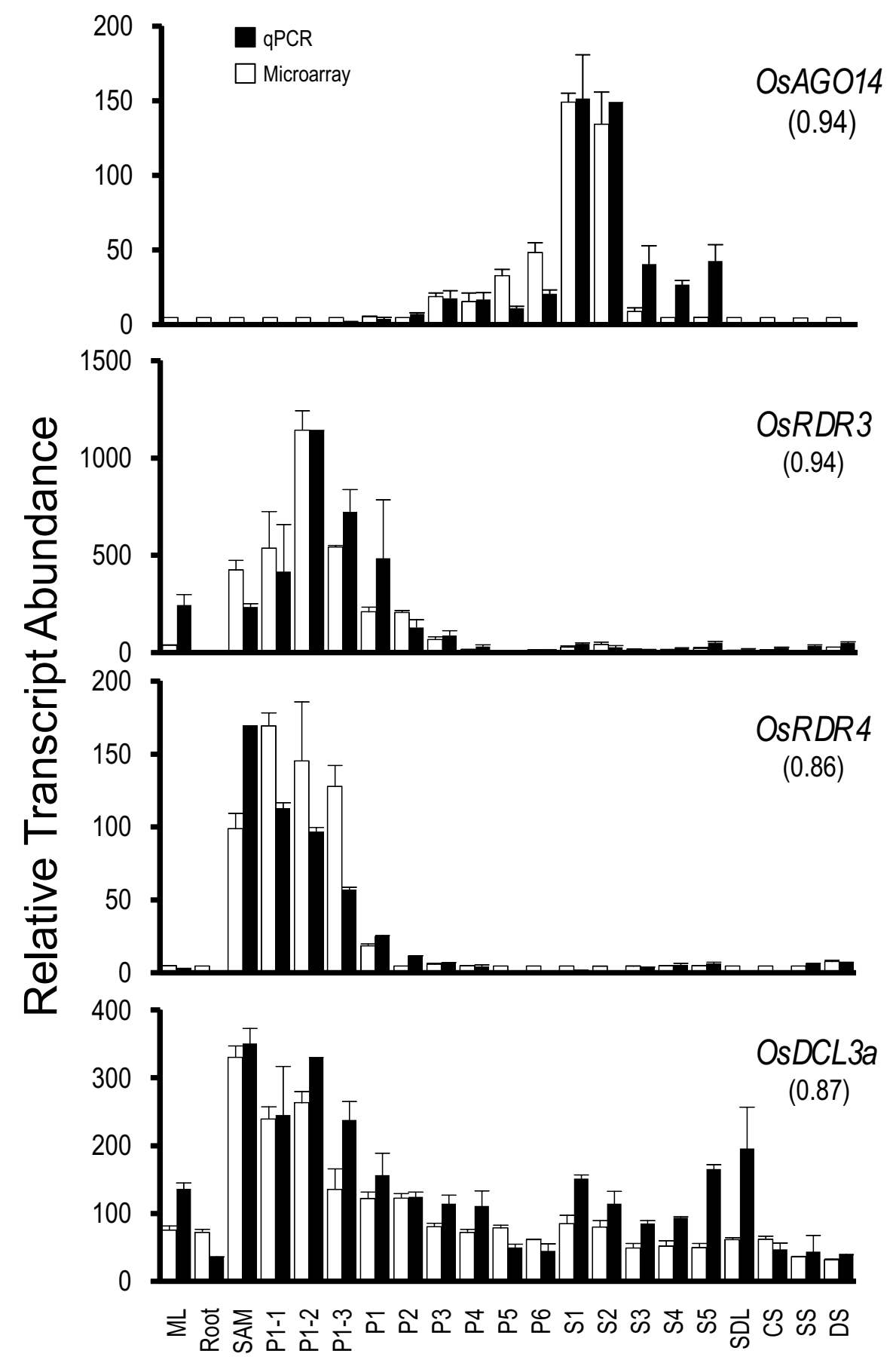

\section{Figure 6}

QPCR results for selected four genes and its correlation with microarray data. Two and three biological replicates have been taken for QPCR and microarray, respectively. Standard error bars have been shown for data obtained using both the techniques. Y-axis represents raw expression values obtained from microarray analysis, QPCR data has been normalized to ease profile matching with that of microarrays. X-axis depicts tissues/developmental stages as described in Figure 4 [see Additional file I]. For each gene the Pearson's correlation values between the two analyses are shown in parenthesis. 
both maize and Arabidopsis genes. It will therefore be interesting to study the role of this gene in rice to validate the speculation of conservation of their roles, based on their similar expression patterns, in dicots and monocots.

\section{Conclusion}

Regulation of gene expression at post-transcriptional level plays a critical role in plant development. RNA interference mediated by activities of Dicers, Argonautes and RNA-dependent RNA polymerases is an important regulatory process that checks transcript accumulation in cells. These components are also shared by other gene-silencing pathways. Dicer-like, Argonautes and RDRs are encoded by small multigene families and rice encodes the largest number of these genes among the plant species analyzed so far. Phylogenetic analysis and localization on rice pseudomolecules have revealed that duplication of genes, both segmental and tandem, have contributed to increase in number of these genes in rice. However, function of only a few of these genes has been established in both rice and Arabidopsis. A key objective of this study was to generate and compile an expression profile data set to facilitate selection of candidate genes for validation of their roles during reproductive phase of plant development and abiotic stress responses. More than 20 genes belonging to these three gene families were observed to express preferentially/specifically during panicle and seed development. This work has provided insights into the probable domains of activity of these genes.

\section{Methods \\ Identification of genes, chromosomal localization and phylogenetic analysis}

Name search and Hidden Markov Model (HMM) analysis was employed to search for Dicer-like, Argonautes and RDRs genes encoded in the rice genome. The sequences were downloaded from TIGR, release 5 http:// www.tigr.org. An HMM profile was generated using HMMER 2.1.1 software package http://hmmer.jane lia.org/ which was then used to search the proteome database of rice available at TIGR using the Basic Local Alignment Search Tool, BLAST with filter off. Amino acid sequences of all the rice genes were downloaded and conserved domains were searched using the Simple Modular Architecture Research Tool (SMART) version 3.4 or National Center for Biotechnology Information Conserved Domain Database, NCBI-CD [39]. The newly identified genes in this study were named on lines of nomenclature used for the previously identified genes and on the basis of their phylogenetic relatedness to other members of the same family. ORF length, and details of encoded proteins (length, PI, molecular weight) were downloaded from TIGR. For proteins whose molecular weight and PI was not available in TIGR, Gene Runner program version 3.04 was used to calculate the same.
Genes were localized on the chromosomes based on their chromosomal positions on psedudomolecules as mentioned in TIGR. For phylogenetic analysis, total protein sequences were downloaded from TIGR and aligned using ClustalX 1.83 program. An unrooted neighbor-joining tree was constructed in ClustalX using default parameters [40]. Bootstrap analysis was performed using 1000 replicates.

\section{Plant material}

Plant tissue for all the panicle and seed stages as well as mature leaf and Y-leaf was collected from field grown rice plants (Oryza sativa ssp. indica var. IR64). Rice seedlings were subjected to abiotic stress treatments, viz. salt, drought and cold as described previously [27].

\section{Microarray Hybridization and Data Analysis}

Affymetrix GeneChip ${ }^{\circledast}$ Rice Genome Arrays representing 49,824 rice transcripts were used to prepare a compendium of transcriptome profiles for 22 stages of vegetative and reproductive development and stress response in rice. Of these, microarray analysis of 17 stages was described previously [27]; deposited in the Gene Expression Omnibus database at the National Center for Biotechnology Information under the series accession numbers GSE6893 and GSE6901). Here, five more stages viz, Y-leaf, SAM (shoot apical meristem), P1-I (< 2 mm panicle), P1-II (0.2 to $0.5 \mathrm{~mm}$ panicle) and P1-III (5 to $10 \mathrm{~mm}$ panicle) have been added to emphasize changes in gene expression patterns during initial stages of panicle differentiation and floral primodia emergence in addition to stages of floral organ- and seed development. Total RNA from these five stages was isolated by using TRIzol method (Invitrogen Inc., USA; [18]). After checking the quality on agarose formaldehyde gels, the RNA samples were quantified using spectrophotometer (ND-1000, Nanodrop). Five micrograms of RNA with 260:280 ratios of 1.9-2.0 and 260:230 ratios more than 2.0 was used for cDNA synthesis. Labeling and hybridizations were carried out according to Affymetrix manual for one-cycle target labeling (Affymetrix, Santa Clara, CA). Hybridization was performed in GeneChip ${ }^{\circledast}$ Hybridization Oven 640 for 16 hours at $45^{\circ} \mathrm{C}$ and $60 \mathrm{rpm}$. GeneChips were washed and stained with streptavidin-phycoerythrin using the fluidics protocol EukGE_WS2V5_450 in Affymetrix fluidic station model 450. Finally, chips were scanned using the Gene-Chip ${ }^{\circledast}$ Scanner 3000-6G.

Sixty six cell intensity (CEL) files generated by GeneChip Operating Software (GCOS) were further analyzed using Arrayassist ${ }^{\mathrm{TM}}$ version 5.0 (Stratagene, La Jolla). Data were normalized using GC-RMA algorithm and $\log _{2}$ transformed. To get the expression values, averages of three biological replicates were used. The expression data for Dicer-like, Argonaute and RDR genes was extracted by 
using unique probe-set IDs mentioned for each gene in TIGR. Wherever more than one probe set was available for one gene, the probe set designed from 3' end was given preference. Cluster analysis on rows of expression values was performed by using Euclidean distance metric, and Ward's Linkage rule of hierarchical clustering. Differential expression analysis was performed by taking mature leaf as reference to identify genes expressing at more than twofold level in different stages of reproductive development (panicle and seed), with p-values $\leq 0.05$. Similarly, for identifying stress-induced genes, differential expression analysis was performed by taking seedling as reference with no correction applied and p-values less $\leq 0.05$ [see Additional file 3]. Since the Affymetrix microarrays used in this study did not contain probes representing OsAGO15, data for this gene was extracted from rice MPSS database http://mpss.udel.edu/rice.

\section{Arabidopsis expression analysis}

To analyze the expression of Arabidopsis genes, Affymetrix GeneChip ${ }^{\circledR}$ ATH1 Genome Array data for 21 stages (55 .cel files) comparable to that used for rice were downloaded from Gene Expression Omnibus (GEO) database at the NCBI under the series accession numbers GSE5620, GSE5621, GSE5623, GSE5624, GSE5629, GSE5630, GSE5631, GSE5632 and GSE5634. The data were imported in ArrayAssist $^{\mathrm{TM}}$ (Stratagene, La Jolla, CA) microarray analysis software wherein GCRMA algorithm was used for normalization and $\log _{2}$ transformation. [see Additional file 4]. The downstream processing and generation of heat maps for selected genes was as described for rice.

\section{QPCR analysis}

Real time PCR reactions were carried out by using the same RNA samples, which were used for microarrays as described earlier [27]. In brief, primers were designed preferentially from 3' end of the genes by using PRIMER EXPRESS version 2.0 (PE Applied Biosystems, USA) with default parameters. Each primer was checked by using BLAST tool for homology with other regions of the genome. $4 \mu \mathrm{g}$ of total RNA was used for first strand cDNA synthesis in $100 \mu$ reaction volume by using high-capacity cDNA Archive kit (Applied Biosystems, USA). Diluted cDNA samples were used for Real time PCR analysis with 200 nM of each primer mixed with SYBR Green PCR master by using ABI Prism 7000 Sequence Detection System and software (PE Applied Biosystems, USA). Actin was used as endogenous control to normalize the variance among samples. Relative expression values were calculated after normalizing against the maximum expression value. These data were further normalized with the normalized expression values obtained from microarrays and bar charts plotted by using Microsoft Excel.

\section{Authors' contributions}

RA and AN generated expression data for mature leaf, panicle and P1-I, P1-II and P1-III stages under the supervision of JPK and AKT. AKT also extended the use of microarray facility. TL participated in computational analysis of gene families, MK and SK conceptualized the analyses, performed computational analysis; MK drafted the manuscript and SK participated in and supervised all the experiments related to panicle development and revised the final version of the manuscript. All authors read and approved the final manuscript.

\section{Additional material}

\section{Additional file 1}

Developmental stages/organs of rice plant analyzed. Click here for file

[http://www.biomedcentral.com/content/supplementary/14712164-9-451-S1.xls]

\section{Additional file 2}

GCRMA normalized expression values obtained for Dicer-like, Argonaute and RDR genes by using rice microarrays data.

Click here for file

[http://www.biomedcentral.com/content/supplementary/1471-

2164-9-451-S2.xls]

\section{Additional file 3}

Differential expression analysis of rice genes in 19 stages/tissues of vegetative and reproductive development by taking mature leaf, root, seedling, SAM and Y-leaf individually as reference.

Click here for file

[http://www.biomedcentral.com/content/supplementary/14712164-9-451-S3.xls]

\section{Additional file 4}

GCRMA normalized expression values for Dicer-like, Argonaute and RDR genes in Arabidopsis from microarray data in public domain (Gene Expression Omnibus, http://www.ncbi.nlm.nih.gov/geo/).

Click here for file

[http://www.biomedcentral.com/content/supplementary/14712164-9-451-S4.xls]

\section{Acknowledgements}

TIGR database resources are acknowledged for making available the detailed sequence information on rice. Expression data for Arabidopsis has been obtained from GEO database at NCBI. Senior Research fellowship by the Council for Scientific and Industrial Research (CSIR) to R.A. and A.N. is also acknowledged. The project has been funded by the Department of Science and Technology and Department of Biotechnology, Government of India.

\section{References}

I. Hamilton AJ, Baulcombe DC: A species of small antisense RNA in posttranscriptional gene silencing in plants. Science 1999, 286(544I):950-952.

2. Volpe TA, Kidner C, Hall IM, Teng G, Grewal SI, Martienssen RA: Regulation of heterochromatic silencing and histone $\mathrm{H3}$ 
lysine-9 methylation by RNAi. Science 2002, 297(5588): 1833-1837.

3. Hall IM, Noma K, Grewal SI: RNA interference machinery regulates chromosome dynamics during mitosis and meiosis in fission yeast. Proc Natl Acad Sci USA 2003, I00(I): 193-198.

4. Mochizuki K, Fine NA, Fujisawa T, Gorovsky MA: Analysis of a piwi-related gene implicates small RNAs in genome rearrangement in tetrahymena. Cell 2002, I I0(6):689-699.

5. Chen $X: A$ microRNA as a translational repressor of APETALA2 in Arabidopsis flower development. Science 2004, 303(5666):2022-2025.

6. Faehnle CR, Joshua-Tor L: Argonautes confront new small RNAs. Curr Opin Chem Biol 2007, I I (5):569-577.

7. Matzke MA, Birchler JA: RNAi-mediated pathways in the nucleus. Nat Rev Genet 2005, 6(I):24-35.

8. Wassenegger M, Heimes S, Riedel L, Sanger HL: RNA-directed de novo methylation of genomic sequences in plants. Cell 1994 76(3):567-576.

9. Xie Z, Johansen LK, Gustafson AM, Kasschau KD, Lellis AD, Zilberman $D$, Jacobsen SE, Carrington JC: Genetic and functional diversification of small RNA pathways in plants. PLoS Biol 2004, 2(5): EI04

10. Margis R, Fusaro AF, Smith NA, Curtin SJ, Watson JM, Finnegan EJ Waterhouse PM: The evolution and diversification of Dicers in plants. FEBS Lett 2006, 580( I 0):2442-2450.

II. Rivas FV, Tolia NH, Song J], Aragon JP, Liu J, Hannon G], Joshua-Tor L: Purified Argonaute2 and an siRNA form recombinant human RISC. Nat Struct Mol Biol 2005, I 2(4):340-349.

12. Hall TM: Structure and function of argonaute proteins. Structure 2005, I3(I0): | 403- | 408.

13. Girard A, Sachidanandam R, Hannon G], Carmell MA: A germlinespecific class of small RNAs binds mammalian Piwi proteins. Nature 2006, 442(7099): 199-202.

14. Yigit E, Batista PJ, Bei Y, Pang KM, Chen CC, Tolia NH, Joshua-Tor L Mitani S, Simard MJ, Mello CC: Analysis of the C. elegans Argonaute family reveals that distinct Argonautes act sequentially during RNAi. Cell 2006, I 27(4):747-757.

15. Nonomura K, Morohoshi A, Nakano M, Eiguchi M, Miyao A, Hirochika $H$, Kurata $N$ : A germ cell specific gene of the ARGO NAUTE family is essential for the progression of premeiotic mitosis and meiosis during sporogenesis in rice. Plant Cell 2007, I 9(8):2583-2594

16. Schiebel W, Pelissier T, Riedel L, Thalmeir S, Schiebel R, Kempe D, Lottspeich F, Sanger HL, Wassenegger M: Isolation of an RNAdirected RNA polymerase-specific cDNA clone from tomato. Plant Cell 1998, I O(I 2):2087-2I0I.

17. lyer LM, Koonin EV, Aravind L: Evolutionary connection between the catalytic subunits of DNA-dependent RNA polymerases and eukaryotic RNA-dependent RNA polymerases and the origin of RNA polymerases. BMC Struct Biol 2003, 3:I.

18. Baumberger N, Baulcombe DC: Arabidopsis ARGONAUTEI is an RNA Slicer that selectively recruits microRNAs and short interfering RNAs. Proc Natl Acad Sci USA 2005, 102(33): I I928-I 1933.

19. Henderson IR, Zhang $X$, Lu C Johnson L, Meyers BC Green PJ, Jacobsen SE: Dissecting Arabidopsis thaliana DICER function in small RNA processing, gene silencing and DNA methylation patterning. Nat Genet 2006, 38(6):72I-725.

20. Kidner CA, Martienssen RA: The role of ARGONAUTEI (AGOI) in meristem formation and identity. Dev Biol 2005 , 280(2):504-5I7.

21. Lee YS, Nakahara K, Pham JW, Kim K, He Z, Sontheimer EJ, Carthew RW: Distinct roles for Drosophila Dicer-I and Dicer-2 in the siRNA/miRNA silencing pathways. Cell 2004, I I 7(I):69-8I.

22. Kennerdell JR, Yamaguchi S, Carthew RW: RNAi is activated during Drosophila oocyte maturation in a manner dependent on aubergine and spindle-E. Genes Dev 2002, I6(I5): I 884-I889.

23. Shiu PK, Metzenberg RL: Meiotic silencing by unpaired DNA: properties, regulation and suppression. Genetics 2002. 16 I(4): | $483-1495$.

24. Grishok A, Pasquinelli AE, Conte D, Li N, Parrish S, Ha I, Baillie DL, Fire A, Ruvkun G, Mello CC: Genes and mechanisms related to RNA interference regulate expression of the small temporal RNAs that control C. elegans developmental timing. Cell 200I, I06(I):23-34
25. Liu B, Li P, Li X, Liu C, Cao S, Chu C, Cao X: Loss of function of OsDCLI affects microRNA accumulation and causes developmental defects in rice. Plant Physiol 2005, I39(I):296-305.

26. Nagasaki H, Itoh J, Hayashi K, Hibara K, Satoh-Nagasawa N, Nosaka M, Mukouhata M, Ashikari M, Kitano H, Matsuoka M, et al.: The small interfering RNA production pathway is required for shoot meristem initiation in rice. Proc Natl Acad Sci USA 2007, 104(37): | 4867- | 487|.

27. Arora R, Agarwal P, Ray S, Singh AK, Singh VP, Tyagi AK, Kapoor S MADS-box gene family in rice: genome-wide identification, organization and expression profiling during reproductive development and stress. BMC Genomics 2007, 8:242.

28. Shi Z, Wang J, Wan X, Shen G, Wang X, Zhang J: Over-expression of rice OsAGO7 gene induces upward curling of the leaf blade that enhanced erect-leaf habit. Planta 2007 226(I):99-108.

29. Schmid M, Davison TS, Henz SR, Pape UJ, Demar M, Vingron M, Scholkopf B, Weigel D, Lohmann JU: A gene expression map of Arabidopsis thaliana development. Nat Genet 2005, 37(5):501-506.

30. Gasciolli V, Mallory AC, Bartel DP, Vaucheret H: Partially redundant functions of Arabidopsis DICER-like enzymes and a role for DCL4 in producing trans-acting siRNAs. Curr Biol 2005, I5(16): I494- I500.

31. Parker JS, Roe SM, Barford D: Structural insights into mRNA recognition from a PIWI domain-siRNA guide complex. Nature 2005, 434(7033):663-666.

32. Ma JB, Yuan YR, Meister G, Pei Y, Tuschl T, Patel DJ: Structural basis for 5 '-end-specific recognition of guide RNA by the $A$. fulgidus Piwi protein. Nature 2005, 434(7033):666-670.

33. Nowotny M, Gaidamakov SA, Crouch RJ, Yang W: Crystal structures of RNase $H$ bound to an RNA/DNA hybrid: substrate specificity and metal-dependent catalysis. Cell 2005, 121(7): $1005-1016$

34. Nishimura A, Ito M, Kamiya N, Sato Y, Matsuoka M: OsPNHI regulates leaf development and maintenance of the shoot apical meristem in rice. Plant / 2002, 30(2):189-20I.

35. Sijen T, Fleenor J, Simmer F, Thijssen KL, Parrish S, Timmons L, Plasterk RH, Fire A: On the role of RNA amplification in dsRNAtriggered gene silencing. Cell 200I, I07(4):465-476.

36. Luo Z, Chen Z: Improperly terminated, unpolyadenylated mRNA of sense transgenes is targeted by RDR6-mediated RNA silencing in Arabidopsis. Plant Cell 2007, 19(3):943-958.

37. Xu L, Yang L, Pi L, Liu Q, Ling Q, Wang H, Poethig RS, Huang $H$ : Genetic interaction between the ASI-AS2 and RDR6-SGS3. AGO7 pathways for leaf morphogenesis. Plant Cell Physiol 2006, 47(7):853-863.

38. Alleman M, Sidorenko L, McGinnis K, Seshadri V, Dorweiler JE, White J, Sikkink K, Chandler VL: An RNA-dependent RNA polymerase is required for paramutation in maize. Nature 2006, 442(7100):295-298.

39. Schultz J, Milpetz F, Bork P, Ponting CP: SMART, a simple modular architecture research tool: identification of signaling domains. Proc Natl Acad Sci USA 1998, 95(I I):5857-5864.

40. Saitou N, Nei M: The neighbor-joining method: a new method for reconstructing phylogenetic trees. Mol Biol Evol 1987, 4(4):406-425

4I. Nobuta K, Venu RC, Lu C, Belo A, Vemaraju K, Kulkarni K, Wang W, Pillay M, Green PJ, Wang GL, et al.: An expression atlas of rice mRNAs and small RNAs. Nat Biotechnol 2007, 25(4):473-477. 